\title{
A Model of Crack Electrochemistry
}

\author{
C. A. Oster \\ M. J. Danielson
}

March 1986

Prepared for the U.S. Department of Energy under Contract DE-AC06-76RLO 1830

Pacific Northwest Laboratory Operated for the U.S. Department of Energy by Battelle Memorial Institute 


\title{
DISCLAIMER
}

This report was prepared as an account of work sponsored by an agency of the United States Government. Neither the United States Government nor any agency thereof, nor any of their employees, makes any warranty, express or implied, or assumes any legal liability or responsibility for the accuracy, completeness, or usefulness of any information, apparatus, product, or process disclosed, or represents that its use would not infring,e privately owned rights. Reference herein to any specific commercial product, process, or service by trade name, trademark, manufacturer, or otherwise, does not necessarily constitute or imply its endorsement, recommendation, or favoring by the United States Government or any agency thereof. The views and opinions of authors expressed herein do not necessarily state or reflect those of the United States Government or any agency thereof.

\author{
PACIFIC NORTHWEST LABORATORY \\ operated by \\ BATTELLE \\ for the \\ UNITED STATES DEPARTMENT OF ENERGY \\ under Contract DE-AC06-76RLO 1830
}

\begin{tabular}{|c|c|}
\hline \multirow{2}{*}{\multicolumn{2}{|c|}{ Printed in the United States of America }} \\
\hline & \\
\hline \multicolumn{2}{|c|}{$\begin{array}{l}\text { Available from } \\
\text { Natuonal Technical Intormation Service }\end{array}$} \\
\hline \multicolumn{2}{|c|}{ United States Department of Commerce } \\
\hline \multicolumn{2}{|c|}{5285 Port Royal Road } \\
\hline \multicolumn{2}{|c|}{ Springlield, Virginia 22161} \\
\hline \multicolumn{2}{|c|}{ NTIS Price Codes } \\
\hline \multicolumn{2}{|c|}{ Microfiche A01 } \\
\hline \multicolumn{2}{|c|}{ Printed Copy } \\
\hline & Price \\
\hline Pages & Codes \\
\hline $001-025$ & $\mathrm{~A} 02$ \\
\hline 026-050 & $\mathrm{A} 03$ \\
\hline $051-075$ & A04 \\
\hline $076-100$ & A05 \\
\hline $101-125$ & A06 \\
\hline $126-150$ & $\mathrm{~A} 07$ \\
\hline $151-175$ & $\mathrm{~A} 08$ \\
\hline $176-200$ & A09 \\
\hline $201-225$ & A010 \\
\hline $226-250$ & A011 \\
\hline $251-275$ & A012 \\
\hline $276-300$ & A013 \\
\hline
\end{tabular}




\section{5}

PNL-5821

UC-4

\section{A MODEL OF CRACK ELECTROCHEMISTRY}

C. A. Oster

M. J. Danielson

March 1986

Prepared for the U.S. Department of Energy under Contract DE-AC06-76RLO 1830

Pacific Northwest Laboratory

Richland, Washington 99352 
$$
\text { · }
$$ 
This document describes a rather general mathematical model of crack tip electrochemistry. First the general mass transport problem is discussed along with the chemistry expected to take place within the crack. The final equations used are extracted and the numerical algorithm presented for producing the final approximation to the original problem.

At least two items have been ignored in the paper. A number of models for the crack tip exist. Only one is described here. Initial experience indicates that other geometries may complicate things during computation but have little effect on the final solution.

The second item involves limiting the electrochemistry by solubility limits. Experiments indicate that when precipitation of $\mathrm{Ni}^{++}$occurs there is a dramatic reduction in anodic current. Indeed, examination of the boundary condition and other governing equations indicate that if precipitation occurs over any finite continuous interval which includes the tip, then the total anodic current at the tip vanishes. Hence the crack growth from corrosion stops. This observation indicates that more research is needed to obtain a useful model of the crack tip when precipitation occurs. 
- 
NOMENCLATURE

Not all symbols are defined here. In some cases the symbol is used for "local" discussion and not used in other parts of the document. Such symbols are not included here.

A A term used in the approximation of $Q$ and $R$

B A term used in the approximation of $P$

C A term used in the approximation of $P$

$C_{p} \quad$ Fraction of phosphorus in the alloy $(\%)$

$c_{i} \quad$ Concentration of chemical species $i\left(\mathrm{~mol} / \mathrm{cm}^{3}\right)$

$D_{i} \quad$ Diffusion coefficient for species $i\left(\mathrm{~cm}^{2} / \mathrm{s}\right)$

E Potential (V)

$E_{\text {ext }} \quad$ Potential of bulk fluid versus saturated calomel reference electrode (v)

EIR Potential loss due to resistance to electrical current in the crack fluid (V)

F Faraday constant $=96484.56(\mathrm{C} / \mathrm{mol})$

G Grouping of constants used in the dimensionless system $\left(\mathrm{cm}^{3} / \mathrm{C}\right)$

$i_{a} \quad$ Anodic current density $\left(\mathrm{A} / \mathrm{cm}^{2}\right)$

$i_{N} \quad$ Component of current density from $\mathrm{Ni}\left(\mathrm{A} / \mathrm{cm}^{2}\right)$

$i_{P} \quad$ Component of current density from $P\left(A / \mathrm{cm}^{2}\right)$

h Dimensionless form for $\Delta x(\cdot)$

$j \quad$ Subscript usually denoting the $j^{\text {th }}$ nodal point of the crack discretization

$K$ Dimensionless grouping of constants $(\cdot)$

$K_{E}$ Equilibrium constant $\left(\mathrm{mol} / \mathrm{cm}^{3}\right)$

\& Crack length $(\mathrm{cm})$

$\mathrm{N} \quad$ Subscript used to denote nickel 
$\mathrm{n} \quad$ Number of intervals used in the discretization of the crack

$\mathrm{P}$ Dimensionless form for $\mathrm{Ni}^{++}$concentration $(\cdot)$, also used as a subscript to denote phosphorus

Q Dimensionless form for $\mathrm{H}_{2} \mathrm{O}$ concentration (•)

$\mathrm{R}$ Dimensionless form for $\mathrm{H}_{3} \mathrm{PO}_{4}$ concentration (.), also used for universal gas constant $=8.31441(\mathrm{~J} / \mathrm{mol}-\mathrm{K})$

$\mathrm{S}$ Dimensionless form for $\mathrm{H}^{+}$concentration (•)

$\mathrm{T}$ Dimensionless form for $\mathrm{HSO}_{4}^{-}$concentration $(\cdot)$, also used to denote temperature $(K)$

U Dimensionless form for $\mathrm{SO}_{4}^{--}$concentration (•)

W Dimensionless form for crack width (•)

W' Dimensionless form for grain boundary width (•)

$W^{*} \quad$ Dimensionless form for width of crack at $x^{*}$, the patch point $(\cdot)$

w Crack width $(\mathrm{cm})$

$x \quad$ Dimensionless form for distance along crack length (•)

$x^{-} \quad$ Point along $x$ axis where crack width is equal to $W^{-}(\cdot)$

$X^{*} \quad$ Point along $x$ axis where the parabolic or tip part of the crack profile is joined to the linear part of the crack profile. This is the patch point in the dimensionless system $(\cdot)$

$x \quad$ Distance along crack length $(\mathrm{cm})$

B Transfer coefficient

$\Delta x \quad$ Discretization increment along crack length $(\mathrm{cm})$

$\zeta \operatorname{Exp}(\psi)$, root of the electroneutrality equation (•)

$\theta \quad$ Crack angle $\left({ }^{\circ}\right)$

$\phi \quad$ Diffusion potential ( $V$ )

$\psi \quad$ Dimensionless form for $\phi(\cdot)$

$k$ Electrical conductivity of the fluid within the crack $\left[(\Omega-\mathrm{cm})^{-1}\right]$

$\infty \quad$ Superscript used to denote properties of the bulk fluid. 


\section{CONTENTS}

SUMMARY

NOMENCLATURE

1. INTRODUCTION

2. BASIC EQUATIONS

3. ANALYTICAL SOLUTION

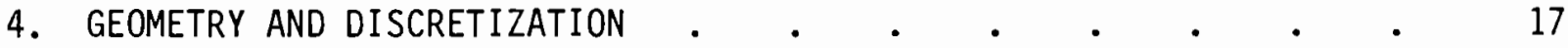

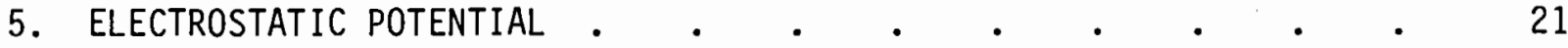

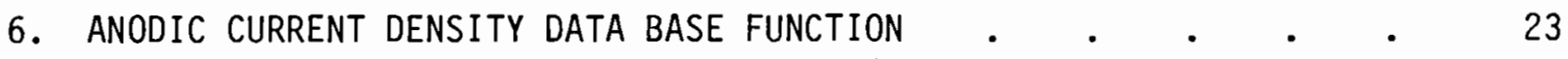

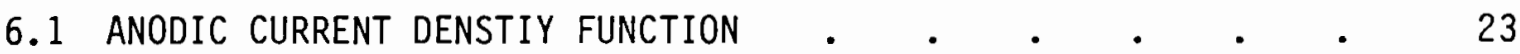

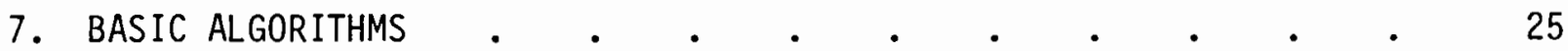

7.1 INITIAL ESTIMATES FOR THE CENTRAL ALGORITHM $\quad$ • $\quad$ • $\quad$ • 25

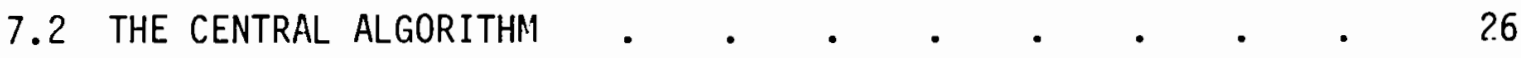

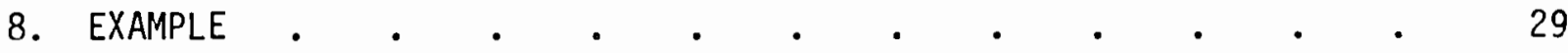

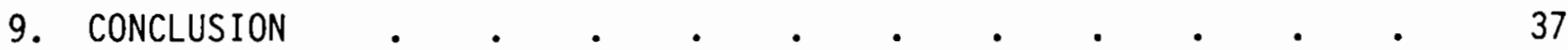

10. ACKNOWLEDGMENT •

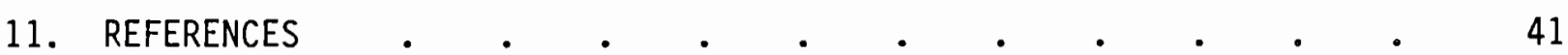

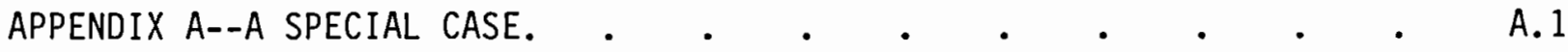

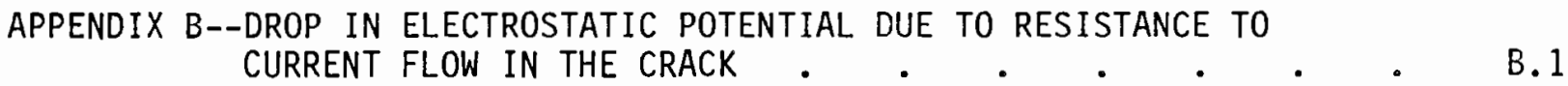

APPENDIX C--A QUADRATURE RULE FOR RATIONAL INTEGRANDS HAVING LINEAR NUMERATOR AND DENOMINATOR.$\quad \cdot \quad \cdot \quad \cdot \quad \cdot \quad \cdot \quad \cdot \quad$.

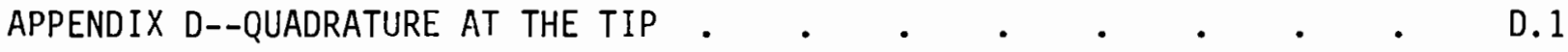

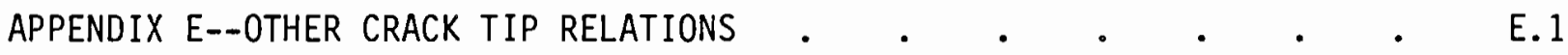


. 


\section{FIGURES}

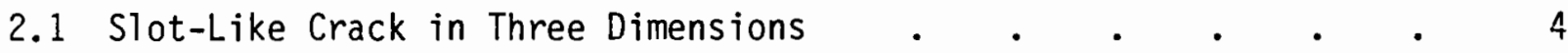

4.1 Two-Dimensional Parabolic Tip Crack Geometry . . . . . . 17

6.1 Contour Plot of the Total Anodic Current Density Function . . 24

8.1 Concentration of $\mathrm{Ni}^{++}$As a Function of Distance Along the Crack . 31

8.2 Concentration of $\mathrm{H}_{2} \mathrm{O}$ As a Function of Distance Along the Crack - 31

8.3 Concentration of $\mathrm{H}_{3} \mathrm{PO}_{4}$ As a Function of Distance Along the Crack . 32

8.4 Concentration of $\mathrm{H}^{+}$As a Function of Distance Along the Crack $\quad 32$

8.5 Concentration of $\mathrm{H} \mathrm{SO}_{4}^{-}$As a Function of Distance Along the Crack . 33

8.6 Concentration of $\mathrm{SO}_{4}^{--}$As a Function of Distance Along the Crack . 33

8.7 Electrostatic Potential As a Function of Distance Along the

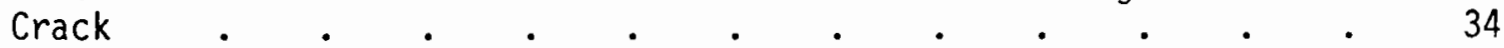

8.8 IR-Drop As a Function of Distance Along the Crack . . . . . 34

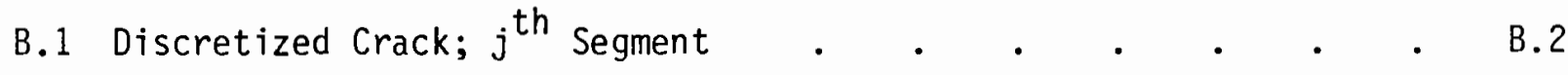

D.1 Resolution of the Current Vector Into Orthogonal Components . $\quad$ D.2 
. 


\subsection{INTRODUCTION}

The growth rate of a crack in metal immersed in an electrolytic solution is a direct consequence of electrochemical reactions occurring within the crack. The rates of these reactions within the crack depend on the local environment and electrode potential within the crack which in turn are largely determined by the mass transfer between the solution in the crack and that in the bulk. Mathematical models are a convenient tool for analyzing mass transfer within a crack (Turnbul1 1983, Shuck and Swedlow 1974a,b).

Here we consider a nickel specimen with phosphorus impurities segregated to the grain boundaries. The crack is propagating along a grain boundary and the specimen is submerged in an acid solution with $\mathrm{pH}<1.0$. 
- 


\subsection{BASIC EQUATIONS}

Central to the physical system under study is mass transport within the electrolytic solution in the crack. This solution mixture consists of an unionized solvent, ionized electrolytes, and uncharged minor components. It is assumed that component concentrations are low so that the solution may be considered as a dilute solution (Newman 1973). Under these conditions the mass transport of any species can be expressed as

$$
\frac{\partial C_{i}}{\partial t}+\underset{\text { Advection }}{\underline{v} \nabla C_{i}}=\underset{\text { Diffusion }}{\nabla} \underline{\underline{\mathrm{D}} \nabla C_{i}}+\underset{\text { Migration }}{\frac{Z_{i} F}{R T} \underline{D} \nabla\left(C_{i} \nabla \phi\right)}+\underset{\text { Reaction }}{r_{i}}
$$

where:

$$
\begin{aligned}
C_{i} & =\text { concentration of } i^{\text {th }} \text { species } & & \left(\mathrm{mol} / \mathrm{cm}^{3}\right) \\
\underline{v} & =\text { velocity vector } & & (\mathrm{cm} / \mathrm{s}) \\
\underline{\underline{D}} & =\text { Diffusion tensor } & & \left(\mathrm{cm}^{2} / \mathrm{s}\right) \\
Z_{i} & =\text { Ionic charge } & & (\cdot) \\
F & =\text { Farady constant }=96484.56 & & (\mathrm{C} / \mathrm{mol}) \\
R & =\text { Gas constant }=8.31441 & & (\mathrm{~J} / \mathrm{mol}-\mathrm{K}) \\
T & =\text { Temperature } & & (\mathrm{K}) \\
\phi & =\text { Diffusion potential } & & (\mathrm{V}) \\
r_{i} & =\text { Reaction term. } & &
\end{aligned}
$$

Values for the two constants $F$ and $R$ are from Cohn and Taylor (1973).

The model is further simplified by making certain assumptions which are now described along with some of the consequences. First, each species concentration remains in steady state. Hence $\partial C_{j} / \partial t=0$. Only simple crack geometrics are considered. Figure 2.1 depicts in three dimensions a narrow crack with parallel sides. This figure leads to the assumption that the area of metal external to the crack is much greater than the crack area. Thus changes in conditions within the crack do not affect the potential of the specimen as a whole. 


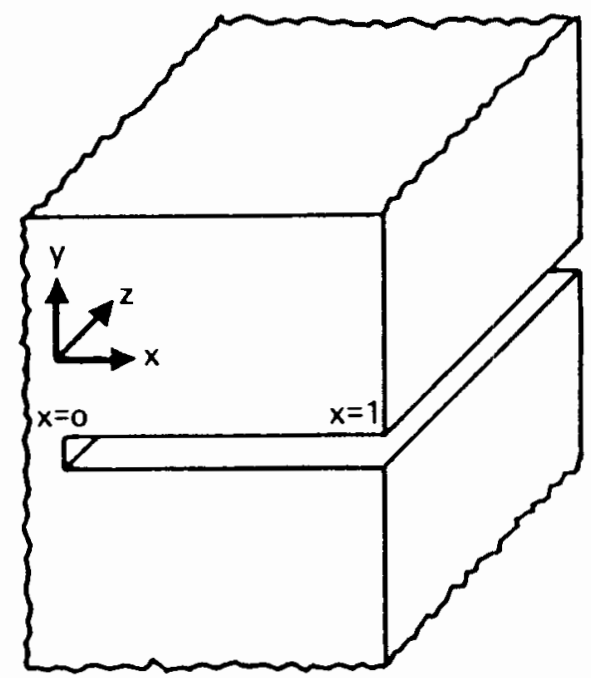

\section{FIGURE 2.1. Slot-Like Crack in Three Dimensions}

The gravitational field is assumed to be in the direction parallel to the $x$ axis and directed toward the crack tip (see Figure 2.1). This implies that natural convection due to density changes can be neglected. The crack is assumed to be static or propagating at such a slow rate that induced advection can be neglected. Mass transport in the $Z$ direction is neglected. This is reasonable if the thickness dimension is much greater than the crack length or if the sides of the crack are sealed (e.g., by a coating). Concentration and potential gradients between the crack walls can be neglected.

To further simplify the mass transport equations, they are averaged by integrating over the $y$ dimension of the crack thus eliminating one independent variable (Turnbull and Thomas 1979).

We shall consider the major chemical species listed in Table 2.1. Included in this table are some of the notations used later. The second column lists the symbol used initially in the discussion. The dimensions of Columns 1 and 2 are $\left(\mathrm{mol} / \mathrm{cm}^{3}\right)$. The bulk of the discussion takes place in a dimensionless geometry. The third column lists the corresponding symbols used in this dimensionless space. 
TABLE 2.1. Primary Chemical Species

$\begin{array}{ccc}\begin{array}{c}\begin{array}{c}\text { Species } \\ \left(\mathrm{mol} / \mathrm{cm}^{3}\right)\end{array} \\ \mathrm{Ni}^{++}\end{array} & \begin{array}{c}\text { "Alias" } \\ \left(\mathrm{mol} / \mathrm{cm}^{3}\right)\end{array} & \begin{array}{c}\text { "Alias" } \\ (\cdot)\end{array} \\ \mathrm{H}_{2}{ }^{\mathrm{O}} & \mathrm{C}_{1} & \mathrm{P} \\ \mathrm{H}_{3} \mathrm{PO}_{4} & \mathrm{C}_{2} & \mathrm{Q} \\ \mathrm{H}^{+} & \mathrm{C}_{3} & \mathrm{R} \\ \mathrm{HSO}_{4}^{-} & \mathrm{C}_{4} & \mathrm{~S} \\ \mathrm{SO}_{4}^{--} & \mathrm{C}_{5} & \mathrm{~T} \\ & \mathrm{C}_{6} & \mathrm{U}\end{array}$

The bulk solution is assumed to be $1 \mathrm{~N} \mathrm{H}_{2} \mathrm{SO}_{4}$, thus an associated chemical species to be considered in $\mathrm{H}_{2} \mathrm{SO}_{4}$. We assume complete dissociation for the first hydrogen ion

$$
\mathrm{H}_{2} \mathrm{SO}_{4}-\mathrm{H}^{+}+\mathrm{HSO}_{4}^{-}
$$

and incomplete dissociation for the second hydrogen ion

$$
\mathrm{HSO}_{4}^{-} \longrightarrow \mathrm{H}^{+}+\mathrm{SO}_{4}^{--}
$$

with dissociation constant 0.012 . This second dissociation constant is altered to compensate for the activity coefficient $\gamma$, of sulfate in $1 \mathrm{~N}_{2} \mathrm{SO}_{4}$ (Dobos 1975) producing an equilibrium constant

$$
K_{E}=\frac{0.012}{\gamma}=5.4 \times 10^{-5}\left(\mathrm{~mol} / \mathrm{cm}^{3}\right)
$$

Neither the ionization of phosphoric acid nor the formation of $\mathrm{Ni}(\mathrm{OH})^{+}$are considered because of the low $\mathrm{pH}$. 
Two additional dissolution reactions considered are

$$
\begin{gathered}
\mathrm{Ni} \longrightarrow \mathrm{Ni}^{++}+2 \mathrm{e}^{-} \\
\mathrm{P}+4 \mathrm{H}_{2} \mathrm{O} \longrightarrow \mathrm{H}_{3} \mathrm{PO}_{4}+5 \mathrm{H}^{+}+5 \mathrm{e}^{-} .
\end{gathered}
$$

No cathodic reactions are considered although an electron sink is implied (we use a counter electrode).

The reaction kinetics equation is

$$
i_{a}=\left[5 F k^{\prime}\left(\frac{C_{P}}{100}\right)+2 F k^{\prime \prime}\left(1-\frac{C_{P}}{100}\right)\right] \exp \left\{\frac{\beta F E}{R T}\right\}=i_{P}+i_{N}
$$

where $C_{P}$ is the percent atomic fraction of $P$ in the alloy. If we assume the alloy corrodes uniformly then $k^{\prime}=k^{\prime \prime}$. By defining $k=F k^{\prime}=F k^{\prime \prime}$ we get

$$
i_{a}=k\left[2+\frac{3 C_{p}}{100}\right] \exp \left\{\frac{\beta F E}{R T}\right\}=i_{p}+i_{N}
$$

where

$$
\begin{aligned}
& i_{P}=5 k\left(\frac{C_{P}}{100}\right) \exp \left\{\frac{\beta F E}{R T}\right\} \\
& i_{N}=2 k\left(1-\frac{C_{P}}{100}\right) \exp \left\{\frac{\beta F E}{R T}\right\} .
\end{aligned}
$$

Notice that $i_{P}$ is proportional to $i_{N}$ and that

$$
\frac{i_{p}}{i_{N}}=\frac{5 C_{p}}{2\left(100-C_{P}\right)}
$$


Finally, define

$$
\phi=E-E_{e x t}+E_{I R}
$$

where $E_{\text {ext }}$ is the potential of the bulk fluid, $E_{I R}$ is the change in electrostatic potential due to resistance to current flow in the crack, and $\phi$ is the diffusion potential. EIR and $\phi$ considered together make a contribution to mass transport known as migration. They have another effect on the boundary condition corrosion rate by changing the potential (the driving force) from that of $E_{\text {ext }}$ to some other value determined by $\phi$ and $E_{I R}$.

The system of equations can be separated into groups and written as follows. The mass transport equations are

$$
\left.\begin{array}{c}
N i^{++}: D_{1} \frac{d}{d x}\left[\frac{d C_{1}}{d x}+\frac{2 F}{R T} C_{1} \frac{d \phi}{d x}\right]+\left(\frac{2}{w}\right) \frac{i_{N}}{2 F}=0 \\
H_{2} 0: D_{2} \frac{d}{d x}\left[\frac{d C_{2}}{d x}\right]-4\left(\frac{2}{w}\right) \frac{i_{p}}{5 F}=0 \\
H_{3} P_{4}: D_{3} \frac{d}{d x}\left[\frac{d C_{3}}{d x}\right]+\left(\frac{2}{w}\right) \frac{i_{p}}{5 F}=0
\end{array}\right\}
$$

The reaction kinetics equations are

$$
\begin{aligned}
& \mathrm{HSO}_{4}^{-}: C_{5}=C_{5}^{\infty} \exp \left\{\frac{\mathrm{F}}{\mathrm{RT}} \phi\right\} \\
& \mathrm{SO}_{4}^{--}: C_{6}=C_{6}^{\infty} \exp \left\{\frac{2 \mathrm{~F}}{\mathrm{RT}} \phi\right\} .
\end{aligned}
$$

The incomplete equilibrium equation is

$$
\frac{C_{4} C_{6}}{C_{5}}=K_{E}
$$


The equilibrium constant $K_{E}$ has the value $5.40 \times 10^{-5}\left[\mathrm{~mol} / \mathrm{cm}^{3}\right]$. The electroneutrality equation is

$$
2 C_{1}+c_{4}-c_{5}-2 C_{6}=0
$$

Thus there are seven equations in the seven unknowns $c_{1}, c_{2}, c_{3}, c_{4}, c_{5}, c_{6}$ and $\phi$. Notice that the set of seven equations uncouple into two groups, the second and third mass transport equations are related to the others only through the relationship between $i_{N}$ and $i_{p}$.

The three differential equations require boundary conditions which are given by

$$
\begin{array}{clc}
\text { at } \mathrm{x}=2 & & \text { (crack mouth) } \\
\mathrm{Ni}^{++} & : & \mathrm{C}_{1}=0 \\
\mathrm{H}_{2} \mathrm{O} & : & \mathrm{C}_{2}=\mathrm{C}_{2}^{\infty} \\
\mathrm{H}_{3} \mathrm{PO}_{4} & : & \mathrm{C}_{3}=0 \\
\mathrm{H}^{+} & : & \mathrm{C}_{4}=\mathrm{C}_{4}^{\infty} \\
\mathrm{HSO}_{4}^{-} & : & \mathrm{C}_{5}=\mathrm{C}_{5}^{\infty} \\
\mathrm{SO}_{4}^{--} & : & \mathrm{C}_{6}=\mathrm{C}_{6}^{\infty}
\end{array}
$$

and

$$
\begin{array}{lll}
\text { at } x=0 & \text { (crack tip) } \\
\mathrm{Ni}^{++} & : & \mathrm{D}_{1}\left[\frac{\mathrm{dC}}{\mathrm{dx}}+\frac{2 \mathrm{~F}}{\mathrm{RT}} \mathrm{C}_{1} \frac{\mathrm{d} \phi}{\mathrm{dx}}\right]+\frac{i_{N}}{2 \mathrm{~F}}=0 \\
\mathrm{H}_{2} \mathrm{O}: & \mathrm{D}_{2} \frac{\mathrm{dC} C_{2}}{\mathrm{dx}}-\frac{4 i_{\mathrm{P}}}{5 \mathrm{~F}}=0 \\
\mathrm{H}_{3} \mathrm{PO}_{4}: & \mathrm{D}_{3} \frac{\mathrm{dC}}{\mathrm{dx}}+\frac{\mathrm{i}_{\mathrm{P}}}{5 \mathrm{~F}}=0 .
\end{array}
$$

The boundary conditions at the crack mouth are determined by the concentrations in the bulk fluid. At the crack tip the boundary conditions are determined by the average mass flux relations, where the average is taken over the crack 
width. Along a similar line, it must be noted that the current terms in the differential equations (2.2) are from the crack walls. These differential equations are obtained by integrating over the variable $y$ in (Eq. 2.1). The current terms then come from the boundary conditions applied in this integration step. See Turnbull and Thomas (1979) and Turnbull (1983) for brief discussions of this procedure.

It is desirable to replace the variables in the above equations with dimensionless variables. The following relations define such a set of variables.

$$
\begin{aligned}
& P=\frac{D_{1} C_{1}}{D_{4} C_{4}^{\infty}} \\
& Q=\frac{D_{2} C_{2}}{D_{4} C_{4}^{\infty}} \\
& R=\frac{D_{3} C_{3}}{D_{4} C_{4}^{\infty}} \\
& S=\frac{D_{4} C_{4}}{D_{4} C_{4}^{\infty}} \\
& T=\frac{D_{5} C_{5}}{D_{4} C_{4}^{\infty}} \\
& U=\frac{F}{R T} D_{6} C_{6} \\
& W=\frac{x}{l} \\
& D_{4} C_{4}^{\infty}
\end{aligned}
$$


It is aiso convenient to introduce the following groupings of constants

$$
\begin{aligned}
& K=\frac{D_{6} K_{E}}{D_{5} C_{4}^{\infty}} \\
& G=\frac{\ell}{F D_{4} C_{4}^{\infty}} .
\end{aligned}
$$

By soiving the above reiationships for the originai variables and substituting the results into the governing equations one obtains equations controlling the dimensionless variables.

$$
\begin{aligned}
& \frac{d}{d X}\left[\frac{d P}{d X}+2 P \frac{d \psi}{d X}\right]+G \frac{i_{N}}{W}=0 \\
& \frac{d}{d X}\left[\frac{d Q}{d X}\right]-\frac{8}{5} G \frac{i_{P}}{W}=0 \\
& \frac{d}{d X}\left[\frac{d R}{d X}\right]-\frac{2}{5} G \frac{P}{W}=0 \\
& S=e^{-\psi} \\
& T=T^{\infty} e^{\psi} \\
& U=U^{\infty} e^{2 \psi} .
\end{aligned}
$$

Similarly the original boundary equations are replaced with

$$
\text { at } \left.\begin{array}{rl}
X & =1 \\
P & =0 \\
Q & =Q^{\infty} \\
R & =0 \\
S & =1 \\
T & =T^{\infty} \\
U & =U^{\infty} \\
\psi & =0
\end{array}\right\}
$$


and

$$
\begin{aligned}
& \text { at } X=0 \quad \text { (crack tip) } \\
& \frac{d P}{d X}+2 P \frac{d \psi}{d X}+\frac{1}{2} G i_{N}=0 \\
& \frac{d Q}{d X}-\frac{4}{5} G i_{P}=0 \\
& \frac{d R}{d X}+\frac{2}{5} G i_{P}=0 .
\end{aligned}
$$

In Equations (2.12), (2.13) and (2.14) the current density terms are obtained from average mass flux relations at or near the tip. This is discussed further in Appendix E.

Finally, the electroneutrality equation becomes

$$
\frac{2 P}{D_{1}}+\frac{S}{D_{4}}-\frac{T}{D_{5}}-\frac{2 U}{D_{6}}=0
$$

Substituting $S, T$ and $U$ from Equations (2.8), (2.9) and (2.10) into the electroneutrality equation and rearranging it somewhat yields

$$
\frac{2 U^{\infty}}{D_{6}} e^{3 \psi}+\frac{T^{\infty}}{D_{5}} e^{2 \psi}-\frac{2 P}{D_{1}} e^{\psi}-\frac{K T^{\infty}}{U^{\infty} D_{4}}=0
$$

which is a cubic polynomial in $e^{\psi}$ having only one nonconstant coefficient. More will be said about this later. 


\author{
.
}




\subsection{ANALYTICAL SOLUTION}

To complete the mathematical model one must obtain the current densities $i_{N}$ and $i_{p}$ which appear in the inhomogeneous terms of the differential equations and boundary conditions. An empirical function is used to approximate the total anodic current data. This function depends upon the \%-atomic fraction of phosphorus in the alloy and the electrostatic potential. This function is discussed in detail in a later section. The differential equations given in the previous section are formally integrated to give analytical solutions. The resulting integrals are then approximated by quadrature formulas providing a numerical approximation to the mass transport problem under study.

Integrating the P-differential equation (2.1) over the interval 0 to $X$ and applying the boundary condition (2.12) at $X=0$ yields

$$
\frac{d P}{d X}+2 P \frac{d \psi}{d X}=-\frac{1}{2} G i_{N}(X=0)-G \int_{0}^{X} \frac{i_{N}(\xi)}{W(\xi)} d \xi
$$

The left side of this equation can be expressed in a more compact form which after multiplying through by $\mathrm{e}^{2 \psi(X)}$, results in the following equation

$$
\frac{d}{d X}\left[e^{2 \psi(X)} P\right]=-\frac{1}{2} G i_{N}(X=0) e^{2 \psi(X)}-G e^{2 \psi(X)} \int_{0}^{X} \frac{N}{W(\xi)} d \xi .
$$

Integrating this equation from 1 to $X$ and using boundary condition (2.11) yields

$$
\begin{aligned}
P(X)= & \frac{1}{2} G i_{N}(x=0) e^{-2 \psi(x)} \int_{X}^{1} e^{2 \psi(\xi)} d \xi \\
& +G e^{-2 \psi(x)} \int_{X}^{1} e^{2 \psi(\xi)} \int_{0}^{\xi} \frac{i_{N}(n)}{W(n)} d n d \xi .
\end{aligned}
$$


Similar steps applied to (2.6) and (2.7) using boundary conditions (2.11), (2.13) and (2.14) produces

$$
\begin{aligned}
Q(x)=Q^{\infty} & -\frac{4}{5} G i_{p}(x=0)(1-x) \\
& -\frac{8}{5} G \int_{x}^{1} \int_{0}^{\xi} \frac{i_{p}(\eta)}{W(n)} d \eta d \xi
\end{aligned}
$$

and

$$
\begin{aligned}
R(X)= & \frac{2}{5} G i_{p}(X=0)(1-X) \\
& +\frac{2}{5} G \int_{X}^{1} \int_{0}^{\xi} \frac{i_{p}(n)}{W(n)} d \eta d \xi .
\end{aligned}
$$

It is convenient to separate out the inner integrals appearing in the above equations. Define

$$
\begin{aligned}
& I_{N}(x)=\int_{0}^{X} \frac{i_{N}(n)}{W(n)} d n \\
& I_{P}(X)=\int_{0}^{X} \frac{i_{P}(n)}{W(n)} d n .
\end{aligned}
$$

Also define the functions

$$
\begin{aligned}
& A(X)=\frac{1}{5} G \int_{X}^{1} I_{P}(\xi) d \xi \\
& B(X)=G e^{-2 \psi(X)} \int_{X}^{1} e^{2 \psi(\xi)} I_{N}(\xi) d \xi
\end{aligned}
$$


and

$$
C(X)=\frac{1}{2} G i_{N}(X=0) e^{-2 \psi(X)} \int_{X}^{1} e^{2 \psi(\xi)} d \xi
$$

Then one may write

$$
\begin{aligned}
& P(X)=B(X)+C(X) \\
& R(X)=\frac{2}{5} G i_{p}(X=0)(1-X)+2 A(X) \\
& Q(X)=Q^{\infty}-2[R(X)+2 A(X)] .
\end{aligned}
$$

Some interesting observations can be made about the $P, Q$ and $R$ equations. Each equation consists of two parts, a part obtained from the tip and a part obtained from the rest of the crack. The part obtained from the tip has the appropriate current density $i(X=0)$ as a factor. The second part contains the current density passing through the crack walls, appearing in the integrand of the double integrals.

The integrals in the $P, Q$ and $R$ equations must usually be evaluated numericaliy. One special case occurs when $i_{p}$ is nonzero onty at the tip, i.e., where $X=0$. This case is discussed in Appendix $A$. The next section describes a numerical scheme for evaluating the integrals. 


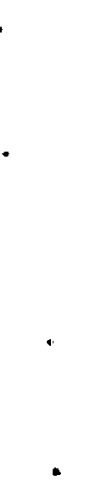




\subsection{GEOMETRY AND DISCRETIZATION}

The crack shape is defined by two functions patched together at the point $X *$ (see Figure 4.1). To the left of $X^{*}$ is the crack tip. In this region the width $W(X)$ is defined as parabolic. Actually, the parabola is $w^{2}=4 p X$. To the right of $X^{*}$ the crack width is linear. Thus the width function is

$$
w(x)=\left\{\begin{array}{lr}
2 \sqrt{4 p X} & 0 \leq x \leq x^{*} \\
W^{*}+2\left(x-x^{*}\right) \tan \theta & x^{*} \leq x \leq 1
\end{array}\right.
$$

where $X^{*}$ is the width at the patch point $X^{*}$, and $\theta$ is the angle between the side and the $X$ axis in the linear part of the crack. The parameter $p$ is the focus of the parabola and is defined as

$$
p=\frac{\left(W^{\star}\right)^{2}}{16 X^{\star}}
$$

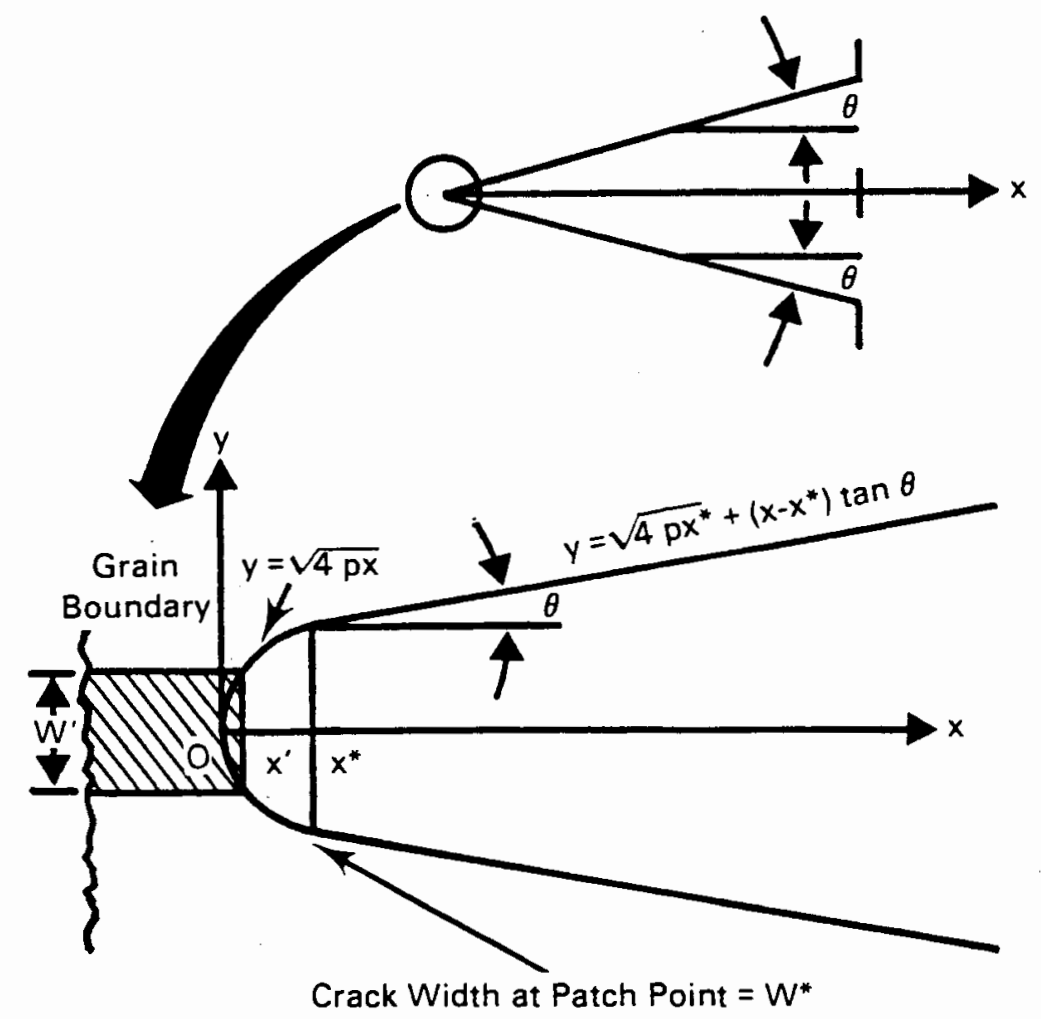

FIGURE 4.1. Two-Dimensional Parabolic Tip Crack Geometry 
We begin by considering the integrals of Equations (3.6) and (3.7). There are some subtleties regarding the crack tip geometry which we choose to ignore during the immediate discussion. They are addressed in Appendixes $D$ and $E$. Appendix $C$ develops a quadrature rule which is exact for integrals of this type where the integrand numerator and denominator are linear functions of $x$.

A discrete system is imposed on the two-dimensional crack by partitioning the $x$ axis into $n$ segments whose end points are denoted by $x_{j}$ and $x_{j+1}$ for $j=1,2, \ldots, n$. The only requirement imposed for now is that $0=x_{1}<x_{2}<\ldots<x_{n+1}=1$. Define $h_{j}=x_{j+1}-x_{j}$ for $j=1,2, \ldots, n$. Define

$$
I_{N j}=I_{N j-1}+\alpha_{j} i_{N}\left(X_{j}\right)+\beta_{j} i_{N}\left(X_{j+1}\right)
$$

where $\alpha_{j}$ and $\beta_{j}$ are the quadrature coefficients defined for the interval $\left(x_{j}, x_{j+1}\right), I_{N 0}=0$ and $j=1,2, \ldots, n$. We then have

$$
I_{N j} \doteq I_{N}\left(x_{j}\right), \quad j=1,2, \ldots, n .
$$

Similarly define

$$
I_{P j}=I_{P j-1}+\alpha_{j} i_{P}\left(X_{j}\right)+\beta_{j} i_{P}\left(X_{j+1}\right)
$$

getting

$$
I_{P j} \doteq I_{P}\left(X_{j}\right), j=1,2, \ldots, n
$$


If the trapezoidal rule (Johnson and Riess 1982) is applied to (3.8), (3.9) and (3.10) we get

$$
\left.\begin{array}{l}
A_{j}=A_{j+1}+\frac{1}{5} G\left(\frac{h_{j}}{2}\right)\left(I_{P_{j}}+I_{P_{j}+1}\right) \\
B_{j}=B_{j+1}+G e^{-2 \psi_{j}}\left(\frac{h_{j}}{2}\right)\left(e^{2 \psi_{j}} I_{N j}+e^{2 \psi_{j+1}} I_{N j+1}\right) \\
C_{j}=C_{j}+\frac{1}{2} G i_{N}(X=0) e^{-2 \psi_{j}}\left(\frac{h_{j}}{2}\right)\left(e^{2 \psi_{j}}+e^{2 \psi_{j+1}}\right)
\end{array}\right\}
$$

for $j=n, n-1, n-2, \ldots, 1$ where $A_{n+1}=B_{n+1}=C_{n+1}=0$ and $\psi_{j} \equiv \psi\left(x_{j}\right)$.

At this point we have five sequences $\left\{I_{N j}\right\},\left\{I_{P_{j}}\right\},\left\{A_{j}\right\},\left\{B_{j}\right\}$ and $\left\{C_{j}\right\}$ which are approximations to the functions $I_{N}\left(X_{j}\right), I_{p}\left(X_{j}\right), A\left(X_{j}\right), B\left(X_{j}\right)$ and $c\left(x_{j}\right)$, respectively. Finally define

$$
\begin{aligned}
& P_{j}=B_{j}+C_{j} \\
& R_{j}=\frac{2}{5} G i_{P}(X=0)\left(1-X_{j}\right)+2 A_{j} \\
& Q_{j}=Q^{\infty}-2\left[R_{j}+2 A_{j}\right]
\end{aligned}
$$

which approximate $P\left(X_{j}\right), R\left(X_{j}\right)$ and $Q\left(X_{j}\right)$, respectively. 
• 


\subsection{ELECTROSTATIC POTENTIAL}

The electroneutrality equation (2.16) may be written as

$$
\frac{2 U^{\infty}}{D_{6}} \zeta^{3}+\frac{T^{\infty}}{D_{5}} \zeta^{2}-\frac{2 P}{D_{1}} \zeta-\frac{K T^{\infty}}{U^{\infty} D_{4}}=0
$$

where $\zeta \equiv \exp (\psi)$. This equation is a cubic polynomial with only the linear coefficient subject to change. By Descartes' Rule of Signs (Johnson and Riess 1982) there is exactly one real positive root and two real negative roots. The positive root is the one of interest and can be obtained by a number of methods. The current code uses Newton's method to find $\zeta$. Then

$$
\begin{aligned}
\psi & =\log _{e} \zeta \\
\phi & =\frac{R T}{F} \psi \\
E & =E_{e x t}+\phi-E_{I R} .
\end{aligned}
$$

The calculation of the $E_{I R}$ term is discussed in Appendix $B$. 



\subsection{ANODIC CURRENT DENSITY DATA BASE FUNCTION}

In this section two functions are discussed. One is an empirical tabular function used to provide the total anodic current as a function of the potential and alloy mix. The second function is the electroneutrality equation.

\subsection{ANODIC CURRENT DENSITY FUNCTION}

To complete the mathematical model one must obtain the current densities $i_{N}$ and $i_{p}$ which appear in the inhomogeneous terms of the differential equations and boundary conditions. Experimental data are used to construct the total anodic current density as a function of the electrostatic potential $E$ and the atomic fraction of phosphorus in the alloy $C_{p}$ (Danielson et al. 1984). Figure 6.1 is a contour plot prepared from the tabulated function used for the total anodic current density. The tabulated current density function is interpolated using the following functional form

$$
i_{a}=k\left(2+\frac{3 C_{p}}{100}\right) \exp \left\{\frac{\beta F}{R T} E\right\}
$$

where $C_{P}$ and $E$ are tabulated at $C_{P 1}, C_{P 2}, \ldots, C_{P I}$ and $E_{1}, E_{2}, \ldots, E_{j}$, respectively. Denote the tabular values of $i_{a}$ by $i_{a i j}$ for $i=1,2, \ldots$, I and $j=1,2, \ldots, \mathrm{J}$.

$C_{p}$ is fixed for a given specimen (or changes infrequently if it is not fixed). So define $B_{j} \equiv \beta_{j} F / R T$. Then construct two arrays $\left\{k_{j}\right\}$ and $\left\{\beta_{j}\right\}$ as follows. First locate $i$ such that $C_{p i} \leq C_{p}<C_{P i+1}$, then compute

$$
I_{j} \equiv \frac{i_{a i j}+\left(\frac{C_{p}-C_{P i}}{C_{P i+1}-C_{P i}}\right)\left(i_{a i+1, j}-i_{a i j}\right)}{2+\frac{3 C_{P}}{100}}
$$




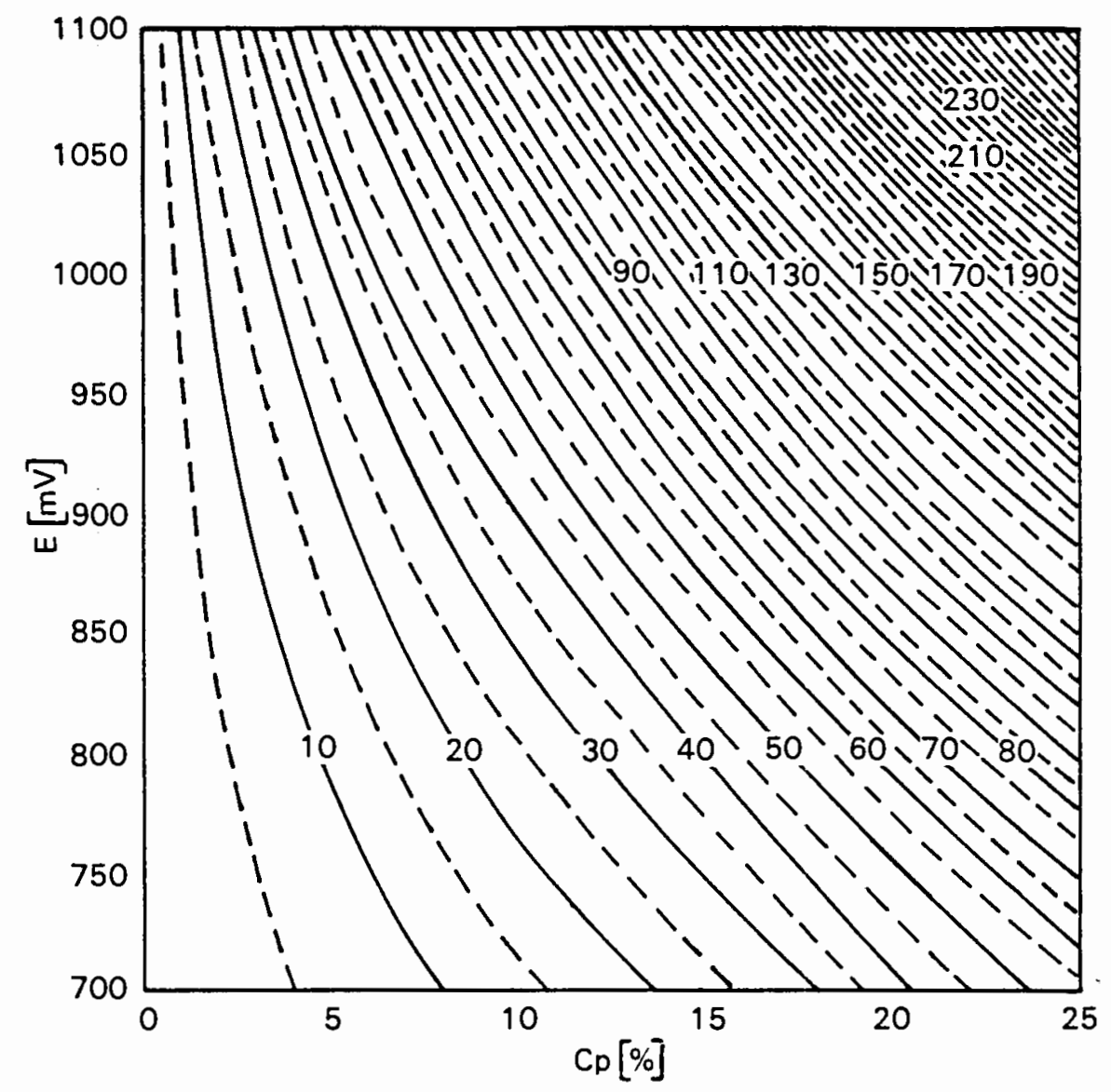

FIGURE 6.1. Contour Plot of the Total Anodic Current Density Function

for $j=1,2, \ldots, J$. Finally, for each $j=1,2, \ldots, J-1$ solve for $k_{j}$ and $B_{j}$ from

$$
\begin{aligned}
\log _{e}\left(I_{j}\right) & =\log _{e}\left(k_{j}\right)+B_{j} E_{j} \\
\log _{e}\left(I_{j+1}\right) & =\log _{e}\left(k_{j}\right)+B_{j} E_{j+1} .
\end{aligned}
$$

Then for $E$ in the range $E_{j} \leq E<E_{j+1}$ the current densities are given by

$$
\begin{gathered}
i_{N}\left(C_{P}, E\right)=2 k_{j}\left(1-\frac{C_{P}}{100}\right) \exp \left\{B_{j} E\right\} \\
i_{P}\left(C_{P}, E\right)=5 k_{j}\left(\frac{C_{P}}{100}\right) \exp \left\{B_{j} E\right\} .
\end{gathered}
$$

The total anodic current is the sum of these two quantities. 


\subsection{BASIC ALGORITHMS}

In this section it will be convenient to introduce some special notation. Consider the sequence $P_{1}, P_{2}, \ldots, P_{n}$ where $P_{j} \equiv P\left(X_{j}\right)$ for $j=1,2, \ldots, n$. We shall use the notation $\left\{P_{j}\right\}$ to denote the entire sequence $P_{1}, P_{2}, \ldots, P_{n}$ or $P_{j}, j=1,2, \ldots, n$. One word of caution is put forth here. Use of $\left\{P_{j}\right\}$ does not imply that $j=1,2, \ldots, n$ in that order. It is also possible that $j=n$, $n-1, \ldots, 1$.

\subsection{INITIAL ESTIMATES FOR THE CENTRAL ALGORITHM}

If a similar problem has been solved earlier, the concentration for $P$ at $x_{i}, i=1,2, \ldots, n$ from that solution might be a good starting point. Experience shows that the procedure described below provides a reasonable set of starting values. The parametric form for the cycloid curve which is a maximum height at $X=0$ is

$$
\begin{aligned}
& x=\frac{P-\sin \rho}{\pi}-1 \\
& y=\frac{P_{\max }}{2.2}(1-\cos \rho)
\end{aligned}
$$

Here $\rho$ is the parameter. Given a value for $X \rho$ can be found by applying Newton's method to the first equation. Once $\rho$ is known the value for $y$ can be found. The estimate for $P(X)$ is then taken as $y$. Newton's iteration function can be expressed as

$$
\rho^{(k+1)}=\frac{\sin \rho^{(k)}-\rho^{(k)} \cos \rho^{(k)}+\pi(x+1)}{1-\cos \rho^{(k)}}
$$

If we start at $X=0=X_{1}$ and take $\rho^{(0)}=\pi$ we get immediately that $P\left(X_{1}\right)=P_{\text {max }} / 1.1$. 
Thus our algorithm for generating starting values for $P\left(x_{j}\right), j=2, \ldots, n$ is as follows for $x_{j}, j=2,3, \ldots, n$ :

1. Set $\rho^{(0)}$ equal to the value of $\rho$ obtained for $x_{j-1}$

2. Iterate (7.2) until

$$
\left|\frac{\rho^{(k+1)}-\rho^{(k)}}{\rho^{(k+1)}}\right|<10^{-5}
$$

3. $P\left(X_{j}\right)=P_{\max } / 2.2[1-\rho(k+1)]$

4. Increment $j$ and repeat the above sequence until $j=n+1$.

The value for $P_{\max }$ is taken to be the solubility limit of $P$.

Initially we can set $E_{I R j}=0$ for $j=1,2, \ldots, n$. With the two sequences $\left\{P_{j}\right\}$ and $\left\{E_{I R j}\right\}$ we can compute $\left\{\psi_{j}\right\}$ and the current densities $\left\{i_{N j}\right\}$ and $\left\{i_{P j}\right\}$, etc., leading to the central algorithm which is now described.

\subsection{THE CENTRAL ALGORITHM}

With values for $\left\{P_{j}\right\}$ and $\left\{E_{I R j}\right\}$ use (5.1) and (5.2) to get $\left\{\psi_{j}\right\}$. Then from (6.4) get $\left\{i_{N j}\right\}$ and $\left\{i_{P j}\right\}$. This gives initial values which permit one to carry out the following algorithm. Denote the iteration count by the superscript $k$. Initially $k=0$ then sequentially carry out the steps given below.
A. Compute $\left\{P_{j}^{(k+1)}\right\}$ using (4.4), (4.6) and (4.7)
B. Compute $\left\{E_{I R j}^{(k+1)}\right\}$ using (B.6) and (B.7)
C. Compute $\left\{\psi_{j}^{(k+1)}\right\}$ using (5.1) and (5.2)
D. Compute $\left\{i_{N j}^{(k+1)}\right\}$ and $\left\{i_{P j}^{(k+1)}\right\}$ using (6.4)
E. Compute $\Omega=\max _{j=1, n}\left|i_{N j}^{(k+1)}-i_{N j}^{(k)}\right| / i_{N j}^{(k+1)}$ If $\Omega>10^{-5}$ advance $k$ by 1 and return to Step $A$. Otherwise continue. 
F. Compute $\left\{Q_{j}\right\}$ and $\left\{R_{j}\right\}$ by (4.8) and (4.9).

G. Compute $\left\{S_{j}\right\},\left\{T_{j}\right\}$ and $\left\{U_{j}\right\}$ from (2.8), (2.9) and (2.10).

At this point we have the solution in the dimensionless variables. One can use (2.4) to solve for the concentrations in terms of $\left[\mathrm{mol} / \mathrm{cm}^{3}\right]$. 



\subsection{EXAMPLE}

The data listed in Table 8.1 describe a sample problem. The crack is 1.25 millimeters long, it is 0.01725 micrometers wide at the patch point $X^{*}$ which is located 0.1 micrometer from the crack tip. The walls of the crack diverge from the center line with an angle of one-half degree. The tip is located in a grain boundary which is $10 \mathrm{~A}$ wide. The grain boundary is made up of $25 \%$ phosphorus and $75 \%$ nickel. The crack walls are made up of $100 \%$ nickel. The external potential is 900 millivolts. The electrolytic solution has a $\mathrm{pH}$ value of $0.2676=-\left(3+\log _{10} C_{4}^{\infty}\right)$, electrical conductivity of $0.21(\Omega-\mathrm{cm})^{-1}$ and has concentrations of the various species as shown in Table 8.1.

The results obtained by the crack model are summarized in Table 8.2 and Figures 8.1 through 8.8. Note that the concentrations $c_{1}, c_{2}, \ldots, c_{6}$ have all been multiplied by 1000 for presentation. The crack tip conditions are summarized at the bottom of Table 8.2.

It should be noted that the function $A(X)$ given in Equation (3.8) is linear for this problem. It is the same situation as discussed in Appendix $A$. Since $A(X)$ is linear it follows that both $R(X)$ and $Q(X)$ are also linear. See Equations (3.12) and (3.13). Figures 8.2 and 8.3 display $Q(X)$ and $R(X)$, respectively, after scaling and do show the linearity. 
TABLE 8.1. Input Data for Test Case

$$
\begin{aligned}
& c_{1}^{\infty}=0 \mathrm{~mol} / \mathrm{cm}^{3} \\
& c_{2}^{\infty}=0.0555 \mathrm{~mol} / \mathrm{cm}^{3} \\
& c_{3}^{\infty}=0 \mathrm{~mol} / \mathrm{cm}^{3} \\
& C_{4}^{\infty}=5.4 \times 10^{-4} \mathrm{~mol} / \mathrm{cm}^{3} \\
& C_{5}^{\infty}=4.5 \times 10^{-4} \mathrm{~mol} / \mathrm{cm}^{3} \\
& C_{6}^{\infty}=4.5 \times 10^{-4} \mathrm{~mol} / \mathrm{cm}^{3} \\
& \ell=1.25 \mathrm{~mm} \\
& X *=0.1 \mu \mathrm{m} \\
& W^{*}=0.01725 \mu \mathrm{m} \\
& \theta=0.5^{\circ} \\
& W^{-}=10 \AA \\
& E_{\text {ext }}=900 \mathrm{mV} \\
& C_{p}=\left\{\begin{array}{r}
25 \% \text { at } x=0 \\
0 \text { for } x>0
\end{array}\right. \\
& D_{1}=10^{-5} \mathrm{~cm}^{2} / \mathrm{s} \\
& \mathrm{D}_{2}=10^{-5} \mathrm{~cm}^{2} / \mathrm{s} \\
& D_{3}=10^{-5} \mathrm{~cm}^{2} / \mathrm{s} \\
& D_{4}=5 \times 10^{-5} \mathrm{~cm}^{2} / \mathrm{s} \\
& D_{5}=10^{-5} \mathrm{~cm}^{2} / \mathrm{s} \\
& D_{6}=10^{-5} \mathrm{~cm}^{2} / \mathrm{s}
\end{aligned}
$$




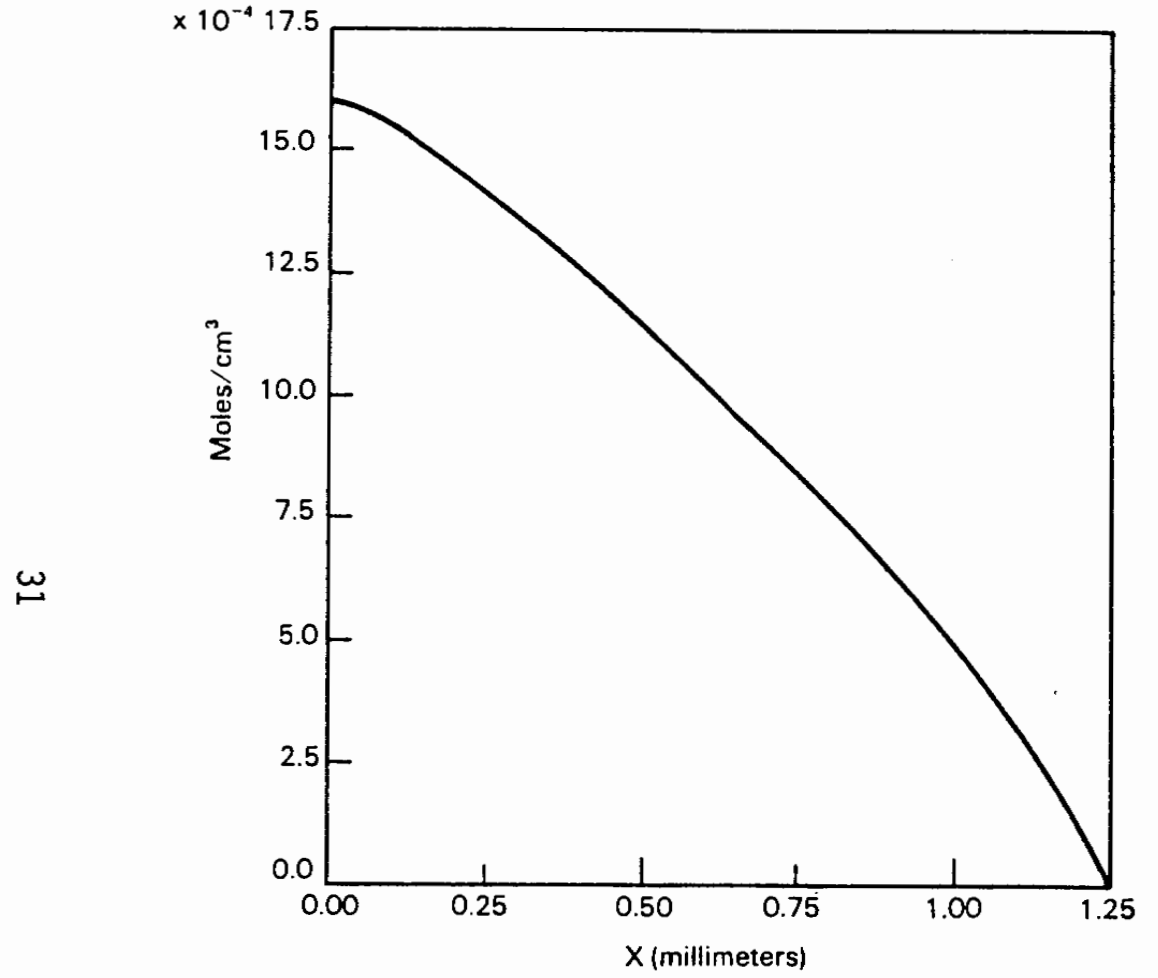

FIGURE 8.1. Concentration of $\mathrm{Ni}^{++}$As a Function of Distance Along the Crack

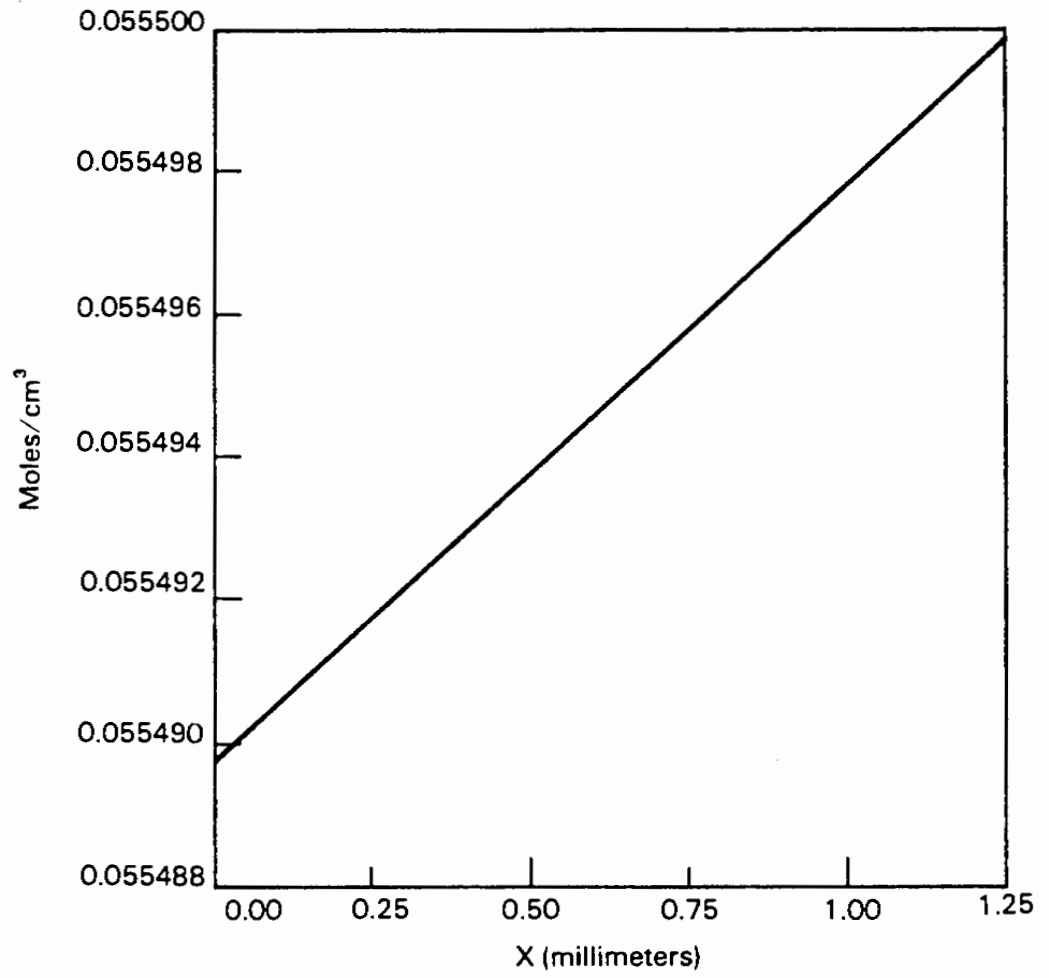

FIGURE 8.2. Concentration of $\mathrm{H}_{2} \mathrm{O}$ As a Function of Distance Along the Crack 


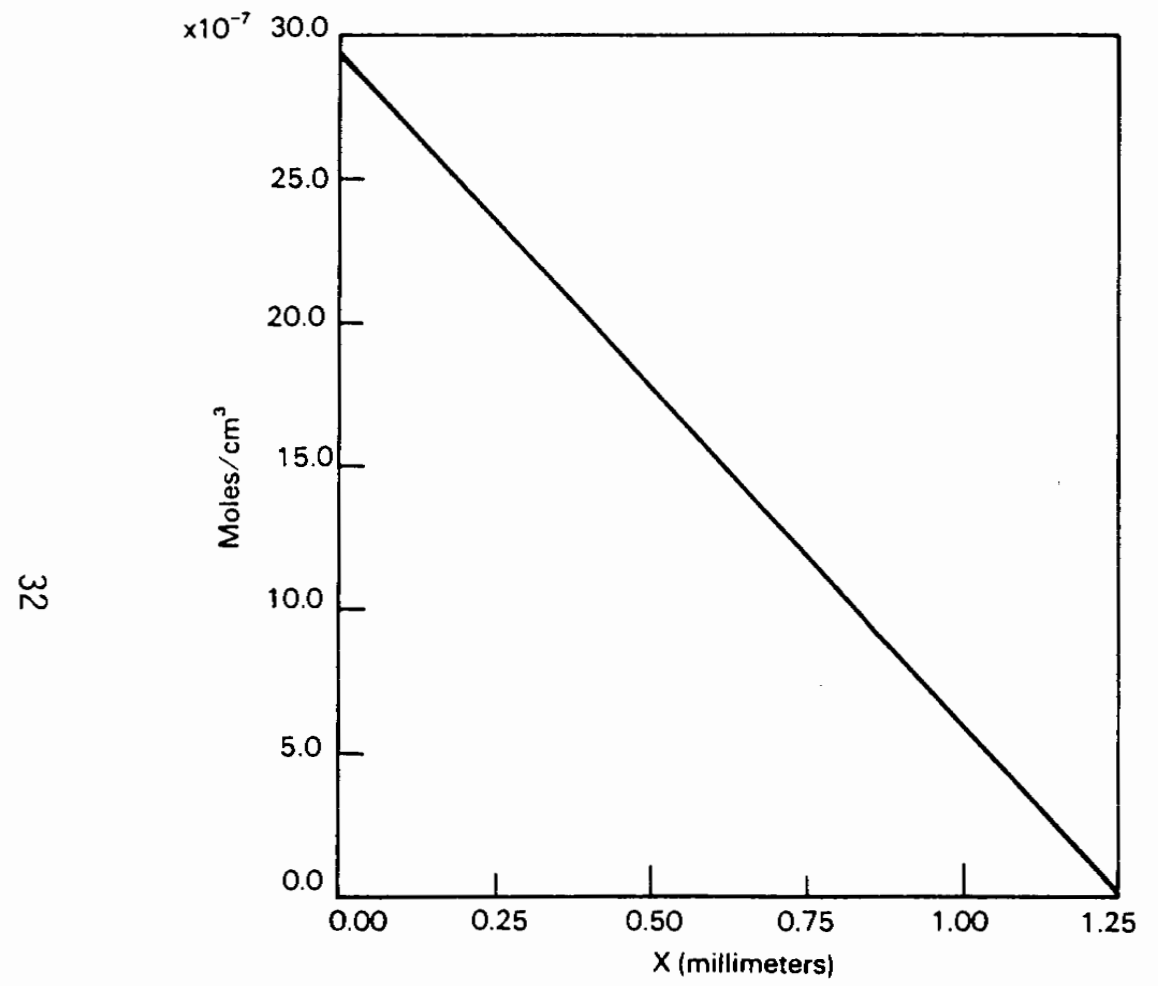

FIGURE 8.3. Concentration of $\mathrm{H}_{3} \mathrm{PO}_{4}$ As a Function of Distance Along the Crack

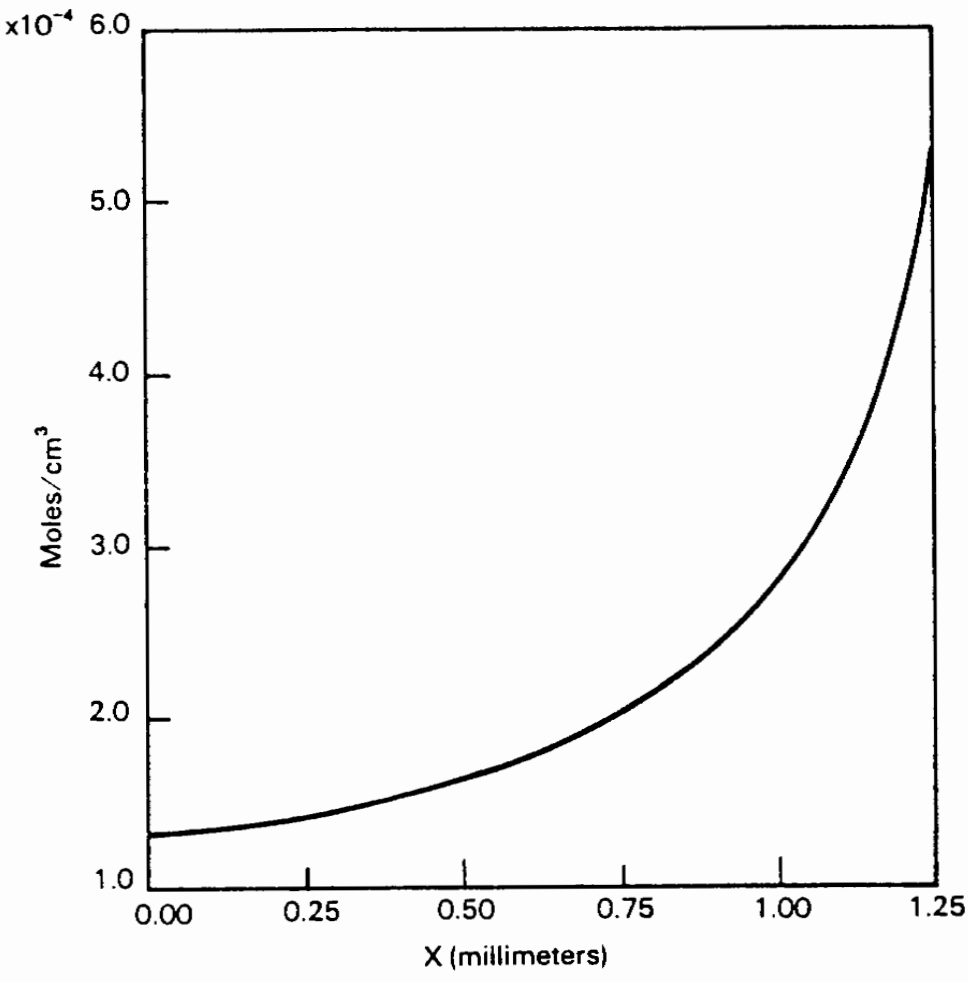

FIGURE 8.4. Concentration of $\mathrm{H}^{+}$As a Function of Distance Along the Crack 


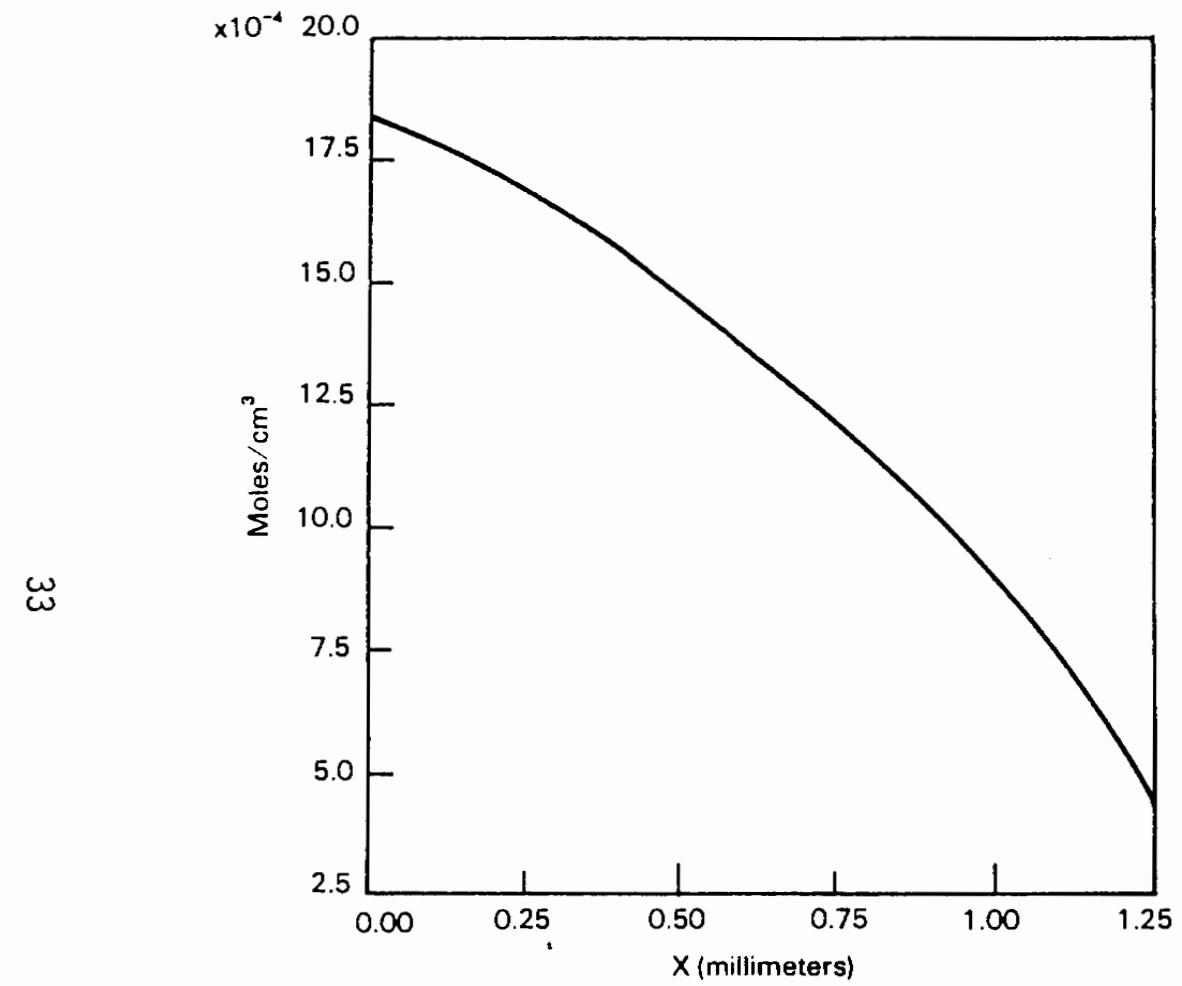

FIGURE 8.5. Concentration of $\mathrm{H} \mathrm{SO}_{4}^{-}$As a Function of Distance Along the Crack

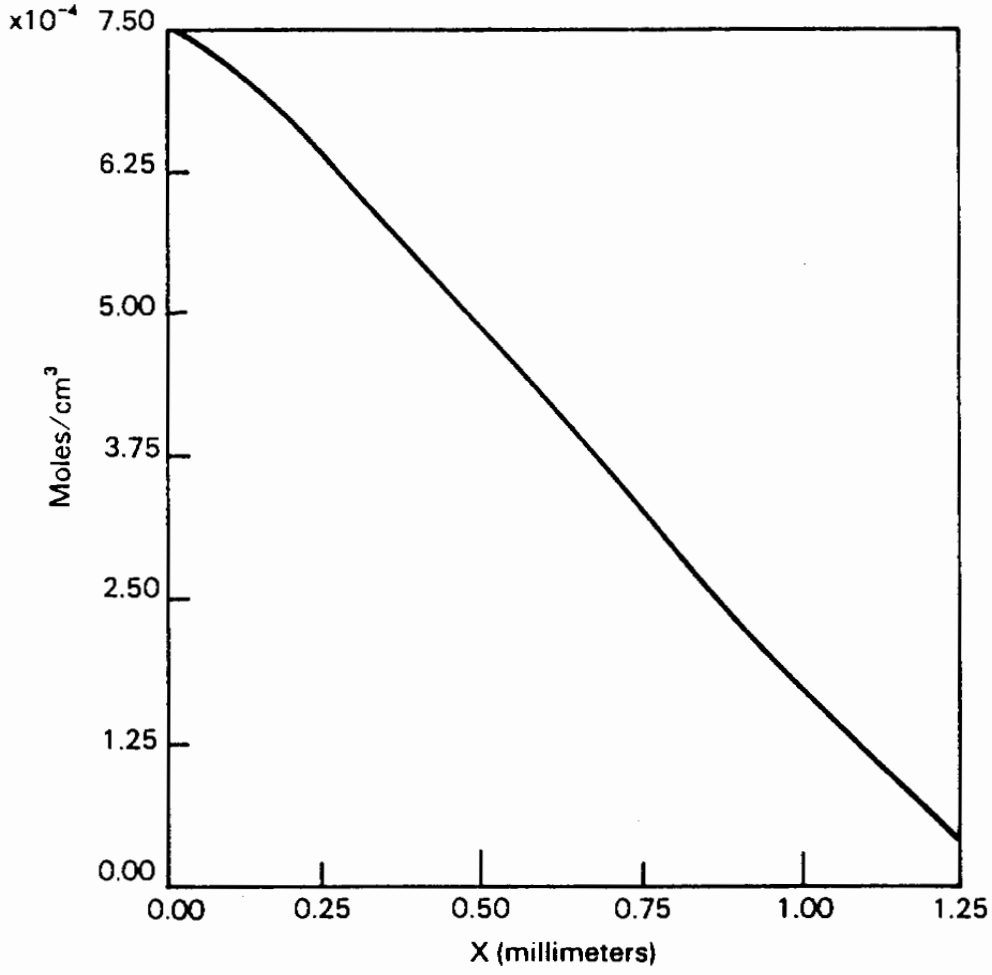

FIGURE 8.6. Concentration of $\mathrm{SO}_{4}^{--}$As a Function of Distance Along the Crack 




FIGURE 8.7. Electrostatic Potential As a Function of Distance Along the Crack

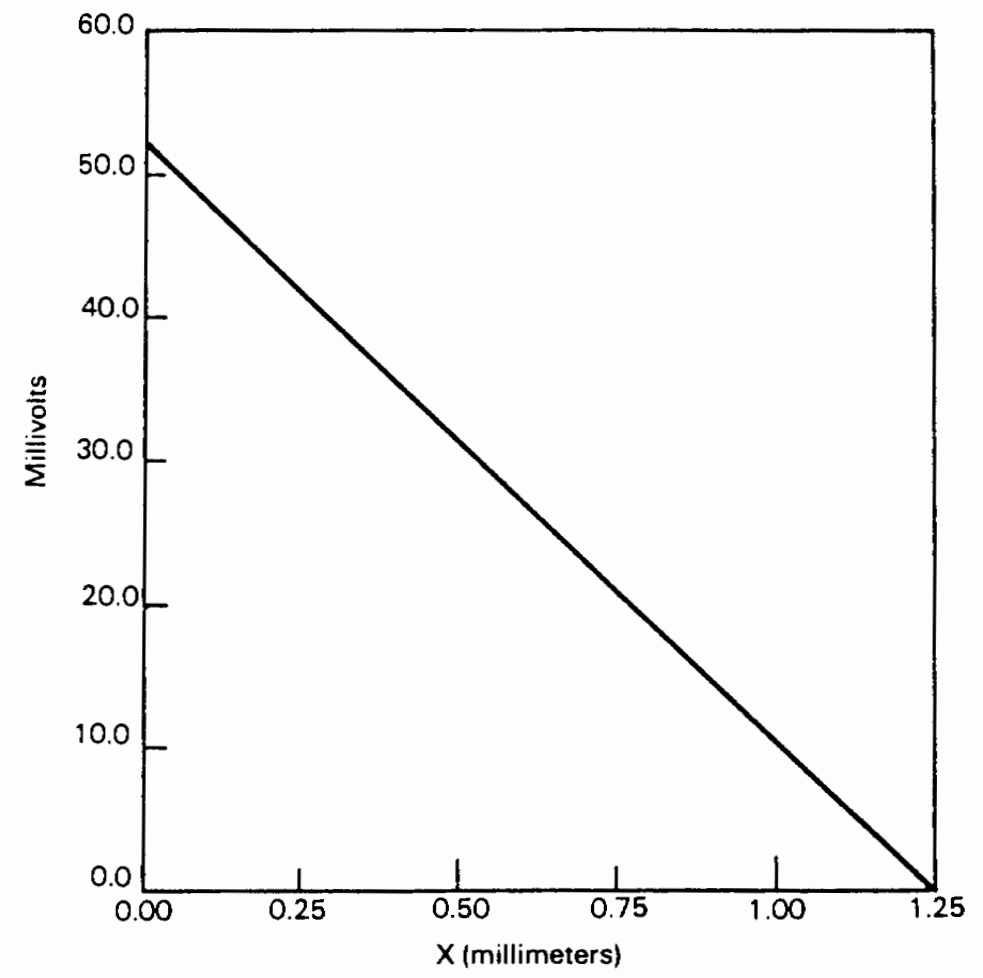

FIGURE 8.8. IR-Drop As a Function of Distance ATong the Crack 
TABLE 8.2. Partial List of Output for Test Case

\begin{tabular}{|c|c|c|c|c|c|c|c|c|}
\hline$X(m m)$ & $\begin{array}{c}\mathrm{Cl}{ }^{\star} \\
{[\mathrm{Ni}+]}\end{array}$ & $\begin{array}{c}\mathrm{C} 2 * \\
{[\mathrm{H} 2 \mathrm{O}]}\end{array}$ & $\begin{array}{c}\mathrm{C} 3^{\star} \\
{[\mathrm{H} 3 \mathrm{PO} 4]}\end{array}$ & $\begin{array}{c}\mathrm{C} 4^{\star} \\
{[\mathrm{H}+]}\end{array}$ & $\begin{array}{c}\mathrm{C5} \\
{[\mathrm{HSO} 4-]}\end{array}$ & $\begin{array}{c}\mathrm{C6}^{\star} \\
{[\mathrm{SO} 4--]}\end{array}$ & $\begin{array}{l}\text { Phi } \\
(\pi V)\end{array}$ & $\begin{array}{c}\text { ir-arop } \\
(\mathrm{mV})\end{array}$ \\
\hline 0.0000 & 1.599 & 55.49 & 9.002918 & 0.1325 & 1.835 & 0.7480 & 36.989 & 52.498 \\
\hline 0.0039 & 1.599 & 55.49 & 0.002913 & 0.1325 & 1.834 & 0.7479 & 36.087 & 52.164 \\
\hline 0.0078 & 1.599 & 55.49 & 0.002904 & 0.1325 & 1.834 & 0.7476 & 36.083 & 51.999 \\
\hline 0.9121 & 1.598 & 55.49 & 0.092894 & 0.1325 & 1.834 & 0.7471 & 36.074 & 51.744 \\
\hline $\begin{array}{ll}5 & 0.0167\end{array}$ & 1.596 & 55.49 & 0.002883 & 9.1326 & 1.832 & 0.7462 & 36.059 & 51.492 \\
\hline 0.0218 & 1.594 & 55.49 & 0.002872 & 0.1327 & 1.831 & 0.7451 & 36.039 & 51.233 \\
\hline 0.0273 & 1.592 & 55.49 & 0.002859 & 0.1328 & 1.829 & 0.7436 & 36.014 & 50.962 \\
\hline 0.0334 & 1.589 & 55.49 & 9.902845 & 0.1330 & 1.827 & 0.7419 & 35.984 & 50.676 \\
\hline 0.0400 & 1.585 & 55.49 & 0.902829 & 0.1332 & 1.825 & 6.7398 & 35.948 & 50.370 \\
\hline 0.0472 & 1.581 & 55.49 & 0.002812 & 0.1334 & 1.822 & 9.7373 & 35.905 & 50.042 \\
\hline 0.0550 & 1.577 & 55.49 & 0.902794 & 0.1337 & 1.818 & 0.7344 & 35.855 & 49.689 \\
\hline 0.0636 & 1.571 & 55.49 & 0.002774 & 0.1340 & 1.814 & 0.7311 & 35.797 & 49.309 \\
\hline 0.0730 & 1.565 & 55.49 & 0.002752 & 0.1343 & 1.809 & 0.7273 & 35.730 & 48.897 \\
\hline 9.9832 & 1.557 & 55.49 & 0.002728 & 9.1347 & 1.804 & 0.7230 & 35.653 & 48.452 \\
\hline 0.0943 & 1.549 & 55.49 & 0.902702 & 0.1352 & 1.798 & 0.7180 & 35.564 & 47.970 \\
\hline 0.1064 & 1.540 & 55.49 & 0.002674 & 0.1357 & 1.791 & 0.7124 & 35.464 & 47.446 \\
\hline 0.1197 & 1.529 & 55.49 & 0.002643 & 0.1363 & 1.783 & 9.7061 & 35.349 & 46.878 \\
\hline 0.1342 & 1.517 & 55.49 & 0.002609 & 0.1370 & 1.773 & 0.6989 & 35.219 & 46.251 \\
\hline 0.1500 & 1.504 & 55.49 & ด. 002572 & 0.1378 & 1.763 & 0.6909 & 35.070 & 45.590 \\
\hline 0.1672 & 1.488 & 55.49 & 0.002532 & 0.1387 & 1.752 & 0.6819 & 34.901 & 44.860 \\
\hline 0.1860 & 1.471 & 55.49 & 0.002488 & 0.1398 & 1.739 & 0.6718 & 34.710 & 44.066 \\
\hline 0.2065 & 1.452 & 55.49 & 0.902440 & 0.1409 & 1.724 & 0.6605 & 34.492 & 43.201 \\
\hline 0.2289 & 1.430 & 55.49 & 9.002387 & 9.1423 & 1.708 & 0.6479 & 34.245 & 42.261 \\
\hline 0.2533 & 1.406 & 55.49 & 0.002330 & 0.1439 & 1.689 & 0.5339 & 33.964 & 41.236 \\
\hline 0.2800 & 1.379 & 55.49 & 0.002268 & 0.1457 & 1.668 & 0.6182 & 33.643 & 40.120 \\
\hline 0.3091 & 1.349 & 55.49 & 0.902200 & 0. 1478 & 1.644 & 0.6009 & 33.278 & 38.905 \\
\hline ๑. 3408 & 1.316 & 55.49 & 0.002126 & 0.1502 & 1.618 & 0.5817 & 32.860 & 37.581 \\
\hline 0.3755 & 1.278 & 55.49 & 0.002045 & 0.1530 & 1.588 & 0.5604 & 32.382 & 36.138 \\
\hline 0.4133 & 1.236 & 55.49 & Ø. 901956 & 0.1563 & 1.554 & 0.5369 & 31.832 & 34.565 \\
\hline 0.4545 & 1.189 & 55.49 & 0.901860 & 9.1602 & 1.516 & 0.5110 & 31.198 & 32.851 \\
\hline 0.4995 & 1.137 & 55.49 & 0.001755 & 0.1649 & 1.474 & 0.4826 & 30.462 & 39.983 \\
\hline 0.5486 & 1.979 & 55.49 & 0.901640 & 0.1705 & .1 .425 & 0.4514 & 29.603 & 28.947 \\
\hline 0.6022 & 1.014 & 55.49 & 0.001515 & 0.1773 & 1.370 & 0.4173 & 28.595 & 26.726 \\
\hline 0.6607 & 9.941 & 55.50 & 0.001378 & 0.1858 & 1.308 & 0.3801 & 27.399 & 24.306 \\
\hline 0.7245 & 0.860 & 55.50 & 0.001229 & 0.1965 & 1.237 & 0.3399 & 25.963 & 21.667 \\
\hline 0.7942 & 0.769 & 55.50 & 0.001066 & 0.2103 & 1.155 & 0.2966 & 24.213 & 18.790 \\
\hline 0.8702 & 0.666 & 55.50 & 0.090888 & 0. 2290 & 1.061 & 0.2503 & 22.034 & 15.653 \\
\hline 0.9531 & 0.550 & 55.50 & 0.900694 & g. 2553 & 0.952 & 0.2013 & 19.239 & 12.232 \\
\hline 1.0436 & 0.414 & 55.50 & 0.000483 & 0.2955 & 0.822 & 9.1503 & 15.482 & 8.502 \\
\hline 1.1423 & 9.247 & 55.50 & 0.000252 & 0.3660 & 0.664 & 0.8980 & 9.991 & 4.434 \\
\hline 1.2500 & 0.000 & 55.50 & 0.000000 & 9.5400 & 0.450 & 0.0450 & 0.900 & 0.000 \\
\hline
\end{tabular}

* Concentrations $\mathrm{Cl}, \mathrm{C} 2, \ldots, \mathrm{C} 6$ have been multiplied by $100 \emptyset$ (units are mol/1).

CRACK TIP CONDITIONS: $\quad$ Potential $883.591[\mathrm{mV}]$

Current densities $\left[\mathrm{mA} / \mathrm{cm}^{\star \star 2}\right]$

\begin{tabular}{lccc} 
& CALCULATED & $\mathrm{CP}=25.98$ & $\mathrm{CP}=0.09$ \\
$\mathrm{i}[\mathrm{P}]$ & 73.44 & 73.44 & 9.0009 \\
$\mathrm{i}[\mathrm{Ni}]$ & 88.13 & 88.13 & 0.0943 \\
\cline { 2 - 4 } & 161.57 & 161.57 & 0.0943
\end{tabular}




\subsection{CONCLUSION}

A model of the mass transport within a narrow crack has been developed and discussed. There are several situations which have not been included here. For example, it is known that the concentration of $\mathrm{Ni}^{++}$for electrolytic solutions such as those involved here, is bounded. In fact, the maximum value for $\mathrm{Ni}^{++}$in the test example is 0.0021 . The value obtained at the crack tip was 0.002039 . When the maximum concentration is reached the $\mathrm{Ni}^{++}$would precipitate as nickel sulfate. If precipitation occurs over an extended distance such as from the tip back to, say $X_{z}$, then $d P / d X$ would vanish in this region. Since $P$ is constant $\psi$ would also be constant, and so $d \psi / d X$ vanishes too [see Eq. (5.1)]. By Equation (2.12) it follows that $i_{N}$ vanishes at the tip. It was noted in Section 2 that $i_{p}$ is proportional to $i_{N}$ so $i_{p}$ also vanishes. Thus, the crack stops growing. Experiments show this not to be the case. In short, the model as developed here must be extended to cover the situation where precipitation occurs.

Another area which needs more study is the choice of discretization points $\left\{x_{j}\right\}$. The set used in the sample problem was obtained largely by trial and error. The relative locations of $x^{-}$and $X^{*}$ determine the shape of the tip. The interaction of these two points with $x_{2}$ needs further study as well. 


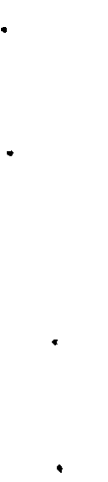




\subsection{ACKNOWLEDGMENT}

This work was funded by the Division of Materials Sciences, Office

of Basic Energy Science, U.S. Department of Energy, under Contract DE-AC06-76RLO 1830 with Battelle Memorial Institute. 


\subsection{REFERENCES}

Cohen, E. R., and B. N. Taylor. 1973. J. Physical and Chemical Reference Data 2(4).

Danielson, M. J., C. A. Oster and R. H. Jones. 1984. "Crack Tip Chemistry Modeling of Intergranular Stress Corrosion Cracks of Nickel Containing Segregated Phosphorus and Sulphur." PNL-SA-123154, Pacific Northwest Laboratory, Richland, Washington. To appear in Proceedings of a Conference on Corrosion Chemistry Within Pits, Crevices and Cracks, London, October 1984.

Dobos, D. 1974. Electrochemical Data. El Sevier Scientific Co., New York, New York.

Johnson, L. W., and R. D. Riess. 1982. Numerical Analysis. Second Edition, Addison-Wesley Publishing Company, Reading, Massachusetts.

Newman, J. 1973. Electrochemical Systems. Prentice Hall, Englewood Cliffs, New Jersey.

Sears, F. W., and M. W. Zemanski. 1952. University Physics. AddisonWesley Press, Inc. pp. 468-469.

Shuck, R. R., and J. L. Swedlow. 1974. "Analysis of Transport in Crack-Like Regions--Part 1. Proceedings of International Conference on Localized Corrosion. NACE-3, Published by National Association of Corrosion Engineers, Houston, Texas. pp. 190-207.

Shuck, R. R., and J. L. Swedlow. 1974. "Analysis of Transport in Crack-Like Regions--Part 2. Proceedings of International Conference on Localized Corrosion. NACE-3, PubTished by National Association of Corrosion Engineers, Houston, Texas. pp. 208-220.

Turnbul1, A. 1983. "A Theoretical Analysis of the Influence of Crack Dimensions and Geometry on Mass Transport in Corrosion Fatigue Crack." Report No. $\operatorname{DMA}(A) 69$, National Physical Laboratory, Teddington Middlesex, England.

Turnbu11, A., and J. G. N. Thomas. 1979. "A Model of Crack Electrochemistry for Steels in the Active State." Report No. DMA(A)11, National Physical Laboratory, Teddington Middlesex, England. 
. 
APPENDIX A

A SPECIAL CASE 
. . 
APPENDIX A

\section{A SPECIAL CASE}

Usually numerical methods must be used to evaluate the integrals appearing in Equations (3.6) through (3.10). There is an interesting case when some of the integrals can be treated analytically. Consider a crack such as the one shown in Figure 4.1 and take $\theta>0$. Let the current density $i_{p}$ be defined by

$$
i_{p}(x)=\left\{\begin{array}{ll}
i^{0} & 0 \leq x \leq x- \\
0 & x-<x
\end{array} .\right.
$$

In this case the integrals (3.7) and (3.8) can be carried out analytically yielding

$$
I_{p}(X)= \begin{cases}\frac{i^{0}}{2 \tan \theta} \log _{e}\left[\frac{W(X)}{W^{\star}}\right] & 0 \leq X \leq X- \\ \frac{i^{0}}{2 \operatorname{Tan} \theta} \log _{e}\left[W^{-}\right] & X \leq X \leq 1\end{cases}
$$

and

$$
A(x)= \begin{cases}\frac{i^{0}}{2 \tan \theta}\left\{\frac{W^{*}}{2 \tan \theta} \log _{e}\left[\frac{W^{-}}{W(x)^{-}}\right]-x \log _{e}\left[\frac{W(x)}{W *}\right]+\log _{e}\left(\frac{W^{-}}{W x^{*}}\right)-\left(x^{-}-x\right)\right\} & 0 \leq x \leq x^{-} \\ \frac{i^{0}(1-x)}{2 \tan \theta} \log _{e}\left[\frac{W^{-}}{W x^{*}}\right] & x^{-} \leq x \leq 1\end{cases}
$$

Finally, we have $R(X)$ and $Q(X)$ by (3.12) and (3.13), respectively.

It should be noted that this case holds so long as $i^{0}$ is a constant. But since the current density is a function of $\psi(X) i_{p}(X)$ would not generally remain constant over an extended interval. 


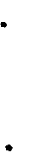


APPENDIX B

DROP IN ELECTROSTATIC POTENTIAL DUE TO

RESISTANCE TO CURRENT FLOW IN THE CRACK 
. 


\section{APPENDIX B}

DROP IN ELECTROSTATIC POTENTIAL DUE TO

RESISTANCE TO CURRENT FLOW IN THE CRACK

Two relationships describe the electrical circuit present in the crack under study. One of these relationships is a conservation law and the other is Ohm's Law. Figure B.1 shows in three dimensions the $j^{\text {th }}$ control volume of the discretized crack. For this discussion assume $X_{j}>X^{*}$. Each element has the same thickness, i.e., $\Delta z$ is constant, and is symmetrical about the $y-z$ plane passing through the center line (the $x$ axis). The first relationship which must be satisfied is a conservation law that states the total current entering the element must equal the total current leaving the element. We assume there is no current flow in the $z$ direction. The area of the top and bottom are the same and are equal to $\Delta z \Delta X_{j} \sec \theta$ where $\theta$ is the crack angle (see Figure 4.1). The area of the left end is $\Delta z W_{j}$ and similarly $\Delta z W_{j+1}$ is the area of the right end. The current density entering the top and bottom is denoted by $i_{j}$ while $i_{c j}$ denotes the current density entering the left end and $i_{c j+1}$ is the current leaving the right end. We thus have the equation

$$
i_{c j} \Delta z w_{j}+2 i_{j} \Delta z \Delta x_{j} \sec \theta-i_{c j+1} \Delta z w_{j+1}=0
$$

This equation can be solved for ${ }^{i}{ }_{c j+1}$

$$
i_{c j+1}=\frac{1}{w_{j+1}}\left\{i_{c j} w_{j}+2 i_{j} \Delta x_{j} \sec \theta\right\}
$$

Now if $i_{c 1}$ and $i_{j}$ for $j=1,2,3, \ldots, n$ are known then $i_{c j}=2,3, \ldots, n$ can be obtained from (B.2). 


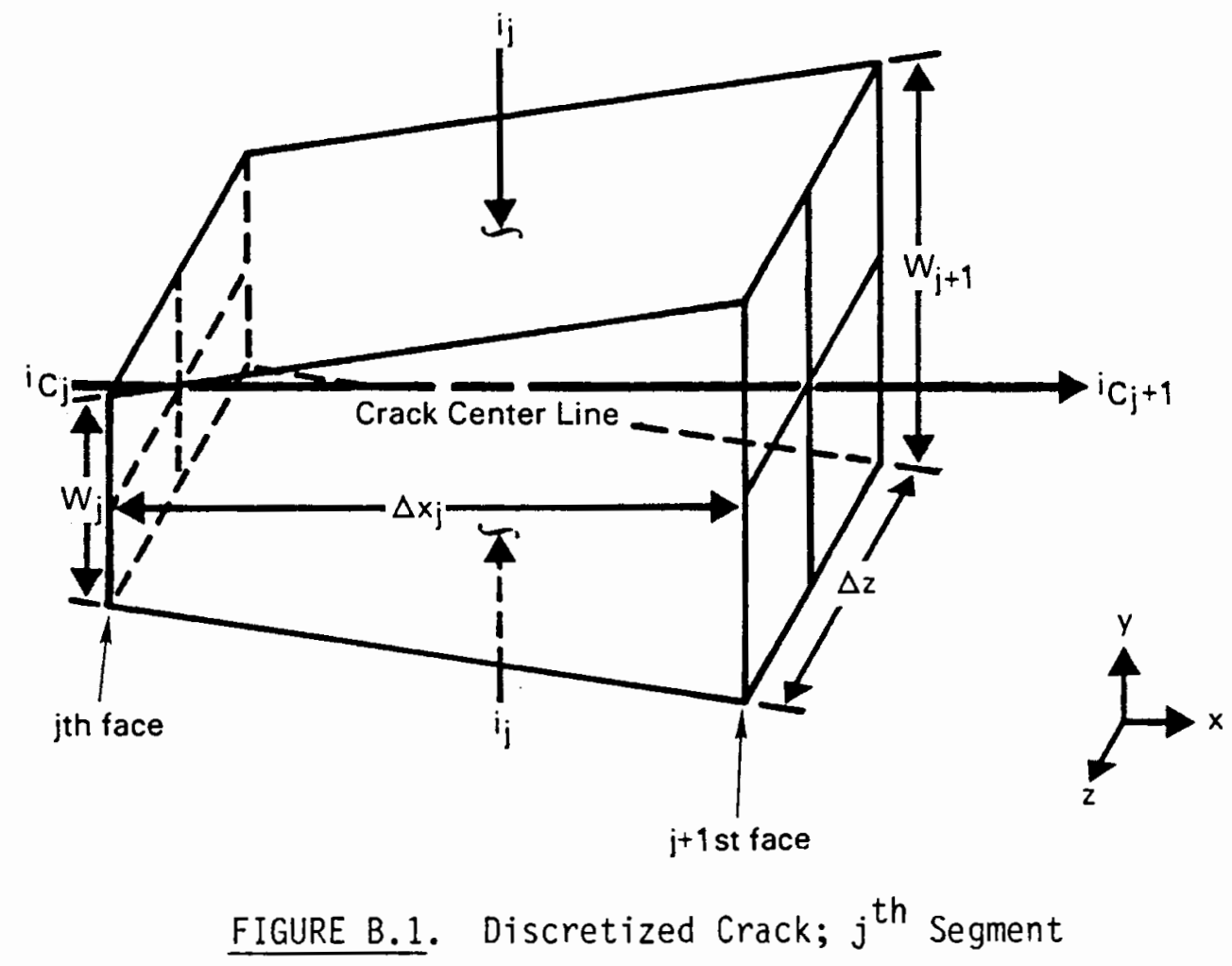

The second relationship which the electrical current must satisfy is known as Ohm's Law (Sears 1952). Applied to the $j^{\text {th }}$ element shown in Figure B.1, Ohm's Law is

$$
\Delta E_{I R j}=\frac{\Delta x_{j}}{K} \frac{x_{j}^{x_{j+1}} w(x) i_{c}(x) d x}{x_{j} \int_{j+1}^{x_{1}} w(x) d x}
$$

where $K$ is the electrical conductivity of the fluid in the crack. The integrals in (B.3) are approximated by the trapezoidal rule if they cannot be integrated 
analytically. Using Equation (4.1) for $W(X)$ the integral in the denominator of (B.3) is just

$$
\int_{j}^{x_{j+1}} w(x) d x=\frac{\Delta x_{j}}{2}\left(w_{j}+w_{j+1}\right)
$$

which is also obtained by the trapezoidal rule. Applying the trapezoidal rule to the integral in the numerator of (B.3) yields

$$
x_{j} \int_{j+1} w(x) i_{c}(x) d x=\frac{\Delta x_{j}}{2}\left[w_{j} i_{c j}+w_{j+1}{ }^{i_{c j+1}}\right] .
$$

Using (B.4) and (B.5) in (B.3) we get

$$
\Delta E_{I R j}=\frac{\Delta x_{j}}{K} \frac{W_{j}{ }^{i} c j+W_{j+1}{ }^{i} c j+1}{W_{j}+W_{j+1}} .
$$

Now the change in potential due to electrical resistance, $E_{I R}$, used in (5.2) is the sum of the $\Delta E_{I R}$ from $X_{j}$ to $X_{n+1}$. That is

$$
E_{I R}\left(X_{j}\right)=\sum_{k=j}^{n} \Delta E_{I R k}
$$

As noted earlier, the above discussion has $x_{j}>X^{*}$. The situation for the part of the crack near the tip where $0 \geq X \geq X *$ is discussed in Appendix E. 
- 
APPENDIX C

A QUADRATURE RULE FOR RATIONAL INTEGRANDS HAVING

LINEAR NUMERATOR AND DENOMINATOR 
.

. 
APPENDIX C

A QUADRATURE RULE FOR RATIONAL INTEGRANDS HAVING

LINEAR NUMERATOR AND DENOMINATOR

Consider the following quadrature formula

$$
\int_{c}^{d} \frac{f(X)}{a+b X} d X=\alpha f(c)+B f(d) .
$$

Let $h=d-c$. Thus if $b \neq 0$ then define $\alpha$ and $\beta$ as

$$
B=\frac{1}{b}\left[1-\left(\frac{a+b c}{b h}\right) \log _{e}\left(\frac{a+b d}{a+b c}\right)\right]
$$

and

$$
\alpha=\frac{1}{b} \log _{e}\left(\frac{a+b d}{a+b c}\right)-\beta
$$

If $b=0$ then define $\alpha$ and $\beta$ as

$$
\alpha=\beta=\frac{h}{2 a} \text {. }
$$

The claim is that (C.1) with (C.2), (C.3) and (C.4) is then exact for any function $f(X)$ which is linear between $c$ and $d$.

To establish this claim first note that if $b=0$ then ( $C .1$ ) becomes the trapazoidal rule which is known to satisfy the claim (Johnson and Riess 1982).

\section{1}


Suppose $b \neq 0$ and take $f(x)$ to be constant over the interval $(c, d)$. Without loss of generality we can take the constant to be unity, then

$$
\int_{c}^{d} \frac{1}{a+b X} d X=\frac{1}{b} \log _{e}\left(\frac{a+b d}{a+b c}\right)=\alpha+\beta
$$

This is just a reordering of (C.3)

Now suppose $f(X)=X$ over the interval $(c, d)$. Again

$$
\begin{aligned}
\int_{c}^{d} \frac{x}{a+b x} d x & =\frac{x}{b}-\left.\frac{a}{b^{2}} \log _{e}(a+b x)\right|_{c} ^{d} \\
& =\frac{h}{b}-\frac{a}{b^{2}} \log \left(\frac{a+b d}{a+b c}\right)=\alpha c+\beta d .
\end{aligned}
$$

Now since $\alpha$ and $\beta$ must also satisfy (C.5) we solve it for $\alpha$ and substitute it into (C.6) yielding eventually (C.2).

Since any linear function is a linear combination of 1 and $X$ it follows that the quadrature (C.1) holds for any 1 inear function $f(X)$. This establishes the claim made above. 
APPENDIX D

QUADRATURE AT THE TIP 


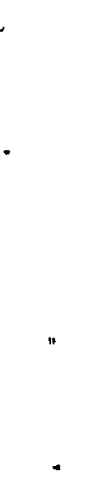




\section{QUADRATURE AT THE TIP}

The integrals of Equations (3.6) and (3.7) must be evaluated as part of the solution process. Here we develop quadrature rules for integrating the parabolic part of the crack, namely near the tip. Thus we seek coefficients $\alpha_{1}$ and $\beta_{1}$ such that

$$
\int_{0}^{x_{2}} \frac{i(\xi)}{W(\xi)} d \xi=\alpha_{1} i(0)+\beta_{1} i\left(x_{2}\right) .
$$

First we examine the more general integral obtained by replacing the limits of integration 0 and $x_{2}$ with $x_{(1)}$ and $x_{(2)}$, respectively. We assume $0 \leq x_{(1)} \leq x_{(2)} \leq x^{\star}$.

The denominator of the integrand is given by Equation (4.1). See also Figure 4.1. The current $i(X)$ is assumed to have constant magnitude for $X$ between $x_{(1)}$ and $x_{(2)}$, and further $i(x)$ is directed perpendicular to the crack wall at the point $X$. The current $i(X)$ is resolved into a vertical component $i_{V}$ and a horizontal component $i_{H}$ (see Figure D.1). Thus

$$
i(x)=i_{H}+i_{V}
$$

where

$$
\begin{aligned}
& i_{V}=|i| \cos \Omega \\
& i_{H}=|i| \sin \Omega
\end{aligned}
$$

where

$$
\tan \Omega=\sqrt{\frac{p}{x}}
$$




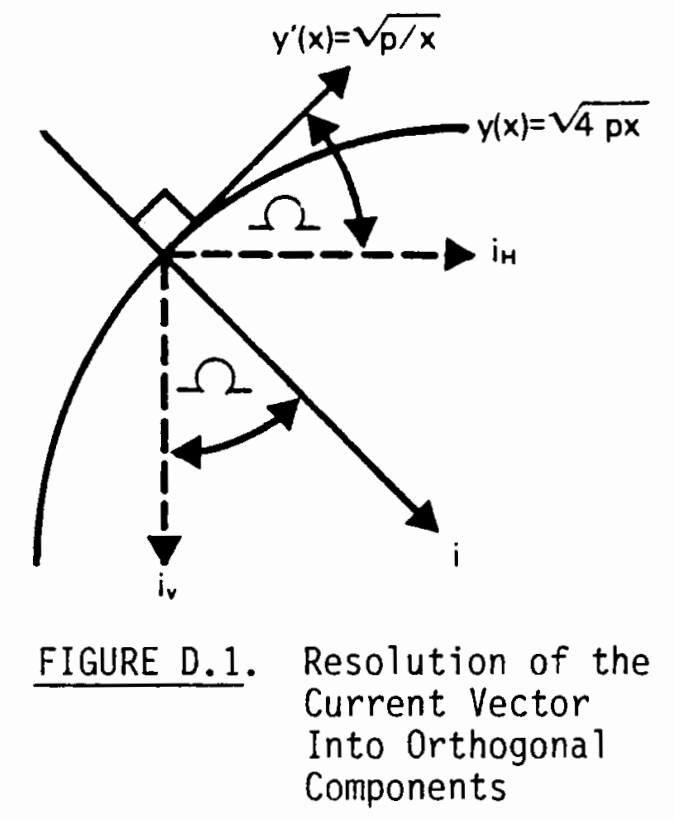

It was noted earlier that the current terms in Equations (3.2) come from applying boundary conditions at the crack wall. they are the vertical components of the current. Hence consider the vertical component of $i$ in the following integral

$$
\int_{x(1)}^{x}(2) \frac{i(\xi)}{W(\xi)} d \xi=|i| \int_{x}^{x} \frac{\cos \left[\tan ^{-1} \sqrt{\frac{p}{\xi}}\right]}{2 \sqrt{4 p \xi}} d \xi \text {. }
$$

Since $\tan \Omega=\sqrt{\mathrm{p} / \mathrm{X}}$ it follows from the Pythagorian relationship that

$$
\cos \Omega=\frac{\sqrt{x}}{\sqrt{x+p}} .
$$


Hence

$$
\begin{aligned}
\int_{x}^{x}(2) \frac{i(\xi)}{W(\xi)} d \xi & =\frac{1 i \mid}{4 \sqrt{p}} \int_{x(1)}^{x}(2) \frac{d \xi}{\sqrt{\xi+p}}=\frac{1 i}{2}\left[\sqrt{\frac{\xi}{2}+1}\right]_{x}{ }_{(1)}^{x_{(2)}} \\
& =\frac{|i|}{2}\left[\sqrt{\frac{x(2)}{p}+1}-\sqrt{\frac{x(1)}{p}+1}\right] .
\end{aligned}
$$

This form is not generally a good one for numerical evaluation. A better form is obtained by reordering the equation to read

$$
\int_{x(1)}^{x} \frac{i v(\xi)}{W(\xi)} d \xi=\frac{|i|}{2}\left[\frac{\frac{x(2)}{p}-\frac{x(1)}{p}}{\sqrt{\frac{x(2)}{p}+1}+\sqrt{\frac{x(1)}{p}+1}}\right] .
$$

Because $X_{2}$ in Equation (D.1) may be greater than the patch point $X^{*}$ (see Figure 4.1) the denominator of the integrand takes a different form for $X$ greater than $X^{*}$. Equation (4.1) gives for $X$ greater than $X^{*}$.

$$
W(X)=W^{*}+2\left(X-X^{*}\right) \tan \theta
$$

Since this part of the crack is similar to that part beyond $x_{2}$, the quadrature rule developed in Appendix $C$ can be applied. We are now in position to develop the coefficients $\alpha_{1}$ and $\beta_{1}$ of Equation (D.1).

There are five separate situations of interest near the crack tip. They are now discussed along with the resulting coefficients. 
1. $x_{2}<x^{\prime}$. Here $x_{(1)}=0$ and $x_{(2)}=x_{2}$ in Equation (D.2), yielding

$$
\begin{aligned}
& \alpha_{1}=\frac{1}{2} \cdot \frac{\frac{x_{2}}{p}}{\sqrt{\frac{x_{2}}{p}+1}+1} \\
& \beta_{1}=0
\end{aligned}
$$

2. $0<x^{\prime}<x_{2}<x^{*}$

$$
\begin{aligned}
& \alpha_{1}=\frac{1}{2} \cdot \frac{\frac{x^{\prime}}{p}}{\sqrt{\frac{x^{\prime}}{p}+1}+1} \\
& \beta_{1}=\frac{1}{2} \cdot \frac{\frac{x_{2}}{p}-\frac{x^{-}}{p}}{\sqrt{\frac{x_{2}}{p}+1}+\sqrt{\frac{X^{\prime}}{p}+1}}
\end{aligned}
$$

3. $0 \leq x^{\star}<x_{2} \leq x^{-}$

$$
\begin{aligned}
& \alpha_{1}=\frac{1}{2} \cdot \frac{\frac{x^{\star}}{p}}{\sqrt{\frac{x^{\star}}{p}+1}+1}+\frac{\cos \theta}{2 \tan \theta} \log _{e}\left[\frac{W_{2}}{W^{\star}}\right] \\
& B_{1}=0
\end{aligned}
$$


4. $0 \leq x^{*}<x^{-} \leq x_{2}$

$$
\begin{aligned}
& \alpha_{1}=\frac{i}{2} \cdot \frac{\frac{x^{\star}}{p}}{\sqrt{\frac{x^{\star}}{p}+1}+1}+\frac{\cos \theta}{2 \tan \theta} \log _{e}\left[\frac{W^{-}}{W^{\star}}\right] \\
& \beta_{1}=\frac{\cos \theta}{2 \operatorname{Tan} \theta} \log _{e}\left[\frac{W_{2}}{W^{*}}\right]
\end{aligned}
$$

5. $0<x^{-} \leq x^{*} \leq x_{2}$

$$
\begin{aligned}
& \alpha_{1}=\frac{1}{2} \cdot \frac{\frac{x^{\prime}}{p}}{\sqrt{\frac{X^{\prime}}{p}+1}+1} \\
& \beta_{1}=\frac{1}{2} \frac{\frac{x^{\star}}{p}-\frac{x^{-}}{p}}{\sqrt{\frac{x^{\star}}{p}+1}+\sqrt{\frac{X^{\prime}}{p}}+1}+\frac{\cos \theta}{2 \tan \theta} \log _{e}\left[\frac{W_{2}}{W^{\star}}\right]
\end{aligned}
$$




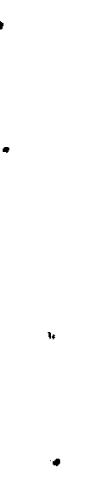


APPENDIX E

OTHER CRACK TIP RELATIONS 


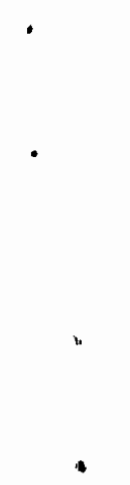


The crack tip shape plays a crucial role in the solution of the difference equations used to approximate conditions within the crack itself. There are three places in the model which require special treatment of the tip conditions. These are the boundary conditions of Equations (2.3) where the horizontal components of the current densities $i_{N}$ and $i_{p}$ are averaged over the crack tip; the current densities $i_{N}$ and $i_{P}$ in the differential equations (2.2) which are the average vertical components of the current densities, and conservation equation (B.2) which require the current density ${ }^{i}{ }_{C l}$ before the other values of $i_{C}$ can be computed.

We define the average horizontal (vertical) current density over the interval $x_{(1)}$ to $x_{(2)}$ of the crack length by the following equation

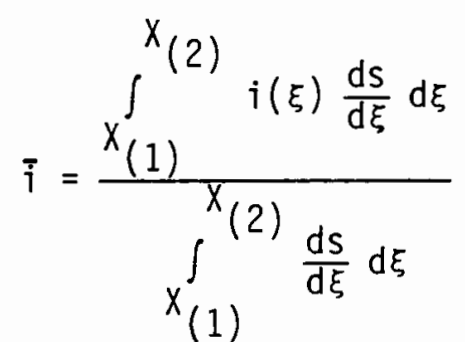

where $d s / d X$ is an infinitesimal increment of arc length along the crack wall, defined by

$$
\frac{d s}{d x}=\sqrt{1+\left(\frac{d y}{d x}\right)^{2}}
$$

For $x$ between 0 and $x^{*}, d y / d x=\sqrt{p / x}$ so

$$
\frac{d s}{d x}=\sqrt{\frac{x+p}{x}}
$$


From Appendix D and more specifically Figure D.1, we get the vertical and horizontal components of the current density

$$
\begin{aligned}
& i_{V}=|i| \sqrt{\frac{x}{x+p}} \\
& i_{H}=|i| \sqrt{\frac{p}{x+p}},
\end{aligned}
$$

respectively.

The distance along the crack wall measured from the tip to some point above $X$ is given by

$$
\begin{aligned}
s(x) & =\int_{0}^{x} \sqrt{\frac{\xi+p}{\xi}} d \xi \\
& =p\left\{\sqrt{\frac{x}{p}} \sqrt{\frac{x}{p}+1}+\log _{e}\left[\sqrt{\frac{x}{p}}+\sqrt{\frac{x}{p}+1}\right]\right\}
\end{aligned}
$$

Thus the denominator of $(E .1)$ is $s\left[X_{(2)}\right]-s\left[X_{(1)}\right]$ where $s(X)$ is given by (E.5) Now observe that

$$
i_{V} \frac{d s}{d \xi}=|i| \quad \frac{\xi}{\xi+p} \cdot \frac{\xi+p}{\xi}=|i|
$$

Substituting this into (E.1) yields

$$
i_{V}=\frac{|i|\left[X_{(2)}-X_{(1)}\right]}{s\left[X_{(2)}\right]-s\left[X_{(1)}\right]}
$$

Similarly

$$
i_{H} \frac{d s}{d \xi}=|i| \sqrt{\frac{p}{\xi+p}} \sqrt{\frac{\xi+p}{\xi}}=|i| \sqrt{\frac{p}{\xi}}=|i| \frac{d y}{d \xi}
$$


gives

$$
i_{H}=\frac{|i|\left\{y\left[x_{(2)}\right]-y\left[x_{(1)}\right]\right\}}{s\left[x_{(2)}\right]-s\left[x_{(1)}\right]} .
$$

If $X_{(1)}=0$ then (E.7) can be used to compute $C_{j}$ of (4.6) and $R_{j}$ of (4.8). Similarly $(E .7)$ can be used for $i_{N}\left(X_{1}\right)$ in (4.2) and $i_{p}\left(X_{1}\right)$ in (4.4). These are the boundary condition approximations for the original problem.

The current density $i_{C i}$ is determined by applying (E.6) and (E.7) to the five cases listed in Appendix D. First, define the two coefficients $\gamma$ and $\delta$ so that

$$
i_{c l}=\gamma i_{1}+\delta i_{2}
$$

then for the five cases we have for Cases 1 and 3

1. $x_{2}<x^{-}$

3. $0 \leq x^{*}<x_{2}<x^{-}$

$$
\begin{aligned}
& \gamma=\left(w_{2}+2 x_{2}\right) / w_{2} \\
& \delta=0
\end{aligned}
$$

and for Cases 2, 4 and 5

2. $0<x^{-}<x_{2}<x^{*}$

4. $0 \leq x^{*}<x^{-} \leq x_{2}$

5. $0 \leq X^{-} \leq X^{*} \leq x_{2}$

$$
\begin{aligned}
& \gamma=\left(W^{-}+2 X^{-}\right) / W_{2} \\
& \delta=\left[\left(W_{2}-W^{-}\right)+2\left(x_{2}-X^{-}\right)\right] / W_{2} .
\end{aligned}
$$



No. of

Copies

OFFSITE

DOE Division of Applied Mathematical Sciences

Washington, DC 20545

Dr. Alan Turnbul 1

Division of Materials Applications

National Physical Laboratory

Teddington

Middlesex TW11 OLW

England

Or. Peter Ford

General Electric R\&D Center

1 River Road

Schenectady, NY 12301

Dr. Ron Ballinger

Nuclear Eng., Bldg. 24-215A

Massachusetts Institute of Technology

77 Massachusetts Avenue

Cambridge, MA 02139

30 DOE Technical Information Center
No. of

Copies

Dr. Larry Eiselstein

SRI International

333 Ravenswood

Menlo Park, CA 94025

ONSITE

DOE Richland Operations Office

J. J. Sutey

73 Pacific Northwest Laboratory

R. C. Adams

M. J. Danielson (20)

J. R. Divine

W. A. GTass

R. H. Jones (20)

G. L. McVay

A. R. 01 sen

C. A. Oster (20)

J. T. A. Roberts

Publishing Coordination (2)

Technical Information (5) 
